\title{
Estimating effectiveness of speed reduction measures for decreasing whale-strike mortality in a high-risk region
}

\author{
R. Cotton Rockwood ${ }^{1, *}$, Jeff Adams ${ }^{2}$, Greg Silber ${ }^{3}$, Jaime Jahncke ${ }^{1}$ \\ ${ }^{1}$ Point Blue Conservation Science, Petaluma, California 94954, USA \\ ${ }^{2}$ National Marine Fisheries Service, Office of Protected Resources, Silver Springs, Maryland 20910, USA \\ ${ }^{3}$ Smultea Environmental Sciences, Washington Grove, Maryland 20880, USA
}

\begin{abstract}
Recent estimates of blue (Balaenoptera musculus) and humpback (Megaptera novaeangliae) whale ship-strike deaths on the US west coast are above the Potential Biological Removal limit determined by the National Marine Fisheries Service. Beginning in 2015, the National Oceanographic and Atmospheric Administration requested voluntary Vessel Speed Reductions (VSR) in the designated shipping routes off San Francisco, California, USA, in order to decrease whale mortality from ship strikes. We applied a ship strike model based on whale density and Automatic Identification System (AIS) vessel data. We bootstrapped speeds from vessels that transited when no VSR was in place to assess the effect of the VSR on strike mortality rates. Finally, we calculated the expected mortality for hypothetical compliance scenarios by programmatically imposing speed caps. Average predicted mortality for the region was 2.7 blue whales and 7.0 humpback whales in a 4 month period. Compared to years prior to the VSR (2012-2014), vessel speeds during the VSR were slower. This lowered blue whale deaths within the shipping lanes by $11-13 \%$ and humpback whale deaths by $9-10 \%$ in $2016-2017$. If $95 \%$ of mariners adhered to recommended 10 knot $(\mathrm{kn})$ limits in the shipping lanes alone, we predicted twice as many blue whale and 3 times as many humpback whale deaths would be avoided relative to current adherence. Adding a $10 \mathrm{kn}$ speed limit (with 95\% cooperation) at the ends of each of the lanes would result in about 5 - and 4 -fold reductions in blue whale and humpback whale mortality, respectively, relative to current practices. Our approach can evaluate ship strikes and mitigation measures for whale populations around the globe.
\end{abstract}

KEY WORDS: Ship strikes - Blue whales - Humpback whales - Encounter model - Speed restriction $\cdot$ Shipping $\cdot$ Marine mammal

\section{INTRODUCTION}

Deaths from collisions with ships (ship strikes) have been identified as one of the top 2 human threats to whale populations around the world (Clapham et al. 1999). Shipping has become ubiquitous in the world's oceans; marine vessel density increased 4-fold worldwide from the early 1990s through 2012 (Tournadre 2014). However, few solutions exist to decrease deadly collisions of vessels with whales (Silber et al. 2012b, 2017). Of the avail-

*Corresponding author: crockwood@pointblue.org able approaches, rerouting vessels and instituting speed restrictions have been identified as the most successful. However, high strike risk areas can experience widely differing ship types, numbers and speeds, whale distribution and behavior, and success of conservation programs (David et al. 2011, McKenna et al. 2012, Bezamat et al. 2015, Nichol et al. 2017, Rockwood et al. 2017). For this reason, we developed a novel approach to (1) estimate the historical effect of speed restrictions using control periods and (2) simulate potential speed restriction and

() The authors 2020. Open Access under Creative Commons by Attribution Licence. Use, distribution and reproduction are unrestricted. Authors and original publication must be credited. 
compliance scenarios. Our approach, based on an encounter model, can gauge speed limit program success, establish expectations for temporal variability in effectiveness and evaluate how increasing cooperation or expanding speed limit areas will change mortality from ship strikes. We applied these approaches to a case study of the shipping approaches to the San Francisco Bay, California, USA. This biologically important whale area, also known as the Gulf of the Farallones, has seen numerous documented instances of ship strikes and there were 24 reported whale mortalities from 2008 to 2018.

Whale populations in waters surrounding North, Central and South America, Europe, Asia and Australasia are at risk of ship strikes (David et al. 2011, Guzman et al. 2013, Bezamat et al. 2015, Priyadarshana et al. 2016, Williams et al. 2016, Peel et al. 2018, Peltier et al. 2019, Smith et al. 2020). While many cetaceans have more coastal distributions, the potential for ship strike impacts in international and offshore waters is also an emerging concern (Pirotta et al. 2019, Schoeman et al. 2020). In many places, ship re-routing, speed restrictions, whale location reporting and navigational best practices are in place or under consideration. Work to explore the difference in effectiveness of voluntary, incentivized and mandatory strike mitigation is helping determine the best approaches (Vanderlaan \& Taggart 2009, Lagueux et al. 2011, McKenna et al. 2012). It is also imperative that managers have information to estimate the likely effect of management and evaluate effectiveness in hindsight. Our approach to modeling and simulating ship strikes under different management and cooperation scenarios has promise for application in many locations around the world.

In the USA, speed restrictions to decrease shipstrike mortality were initially deployed about a decade ago. Driven by the status of the severely depleted North Atlantic right whale, changes in shipping routes and mandatory speed limits were established to decrease mortality from ship collisions in high risk locations along the US eastern seaboard (Silber et al. 2015). Additional research has linked ship speed to collision risk (Conn \& Silber 2013) and the probability of mortality when a strike occurs (Vanderlaan \& Taggart 2009, van der Hoop et al. 2012). Retrospective analysis of regional vessel speed regulations has indicated success at decreasing mortality, with lower strike incidence and right whale population increases in the years immediately following regulation (Laist et al. 2014, van der Hoop et al. 2015). Populations of blue, fin, sperm and humpback whales on the US western coast are less severely depleted than North Atlantic right whales, so efforts there began decades after those implemented along the US eastern seaboard.

On the US west coast, ship-strike deaths as confirmed by stranded carcasses are the number one source of human-caused mortality for blue whales Balaenoptera musculus and the second highest for humpback whales Megaptera novaeangliae (Carretta et al. 2016a). Recently, a modeling approach estimated that 18 blue whales and 22 humpback whales are killed within the Exclusive Economic Zone (EEZ) in waters off California, Oregon and Washington during periods of peak seasonal whale abundance from July to December each year (Rockwood et al. 2017). The analysis also indicated the shipping lanes and surrounding waters outside San Francisco Bay as one of the highest-risk regions for these species. To better understand how ship strikes are affecting blue and humpback whales in this region, and to assess the effectiveness of current management actions, we modeled mortality due to collisions.

The eastern North Pacific stock of blue whales occurs from the Gulf of Alaska to waters of the eastern tropical Pacific Ocean. This blue whale population is estimated to be 1647 individuals, with little evidence of growth over the last 2 decades (Calambokidis \& Barlow 2013). Humpback whale populations occurring along the US eastern North Pacific Ocean coast range from Alaska south to Central America. Two main federal laws protect whales in the USA: the Marine Mammal Protection Act (MMPA) and the Endangered Species Act (ESA). Along the US western coast (California, Oregon and Washington), 1 humpback whale stock is currently recognized under the MMPA, but 2 Distinct Population Segments (DPSs) are now defined by the ESA based on a 2016 status review (Bettridge et al. 2015). The west coast stock of humpback whales is comprised mainly of the endangered Central American DPS, and the threatened Mexico DPS. The best population estimate for the Central American DPS is 411 individuals (Wade et al. 2016), while the total west coast humpback whale population is estimated as 2900 (Carretta et al. 2018). For both blue and humpback whales, the Gulf of the Farallones region has been established as one of the most important feeding areas during summer and fall and is a designated Biologically Important Area (BIA) (Calambokidis et al. 2015).

In the USA, legal protection under the MMPA and the ESA makes killing or harassment of marine mammals illegal without an authorization for incidental take. Since 1994, the MMPA requires the calculation 
of human-caused mortality limits (known as Potential Biological Removal, PBR) for all strategic stocks. PBR is a precautionary metric calculated from a population's minimum abundance estimate, maximum net productivity rate and a recovery factor (Wade 1998). Strong precautionary approaches in marine mammal conservation are needed because existing monitoring programs would only detect a $50 \%$ population decline in fewer than $30 \%$ of species (Taylor et al. 2007). Thus, PBR is an important benchmark for conservation and management of whales in the absence of high certainty, high temporal resolution population estimates. The PBR in west coast US waters is 2.3 for blue and 16.7 for humpback whales (Carretta et al. 2016b, 2018).

In waters off California, blue and humpback whale populations are among those listed as endangered, with special concern over the small size of the Central American humpback whale DPS and the lack of blue whale population growth. Ship strikes are one of the primary causes of mortality for both species (Carretta et al. 2018). Thousands of large commercial vessels transit these whale-rich areas every year heading to and from California's 3 largest and busiest ports: Los Angeles, Long Beach and San Francisco Bay port complex. These ports process approximately half the shipped goods in the USA with the combined San Francisco Bay Area ports experiencing 3534 calls in 2016 (J. Berge pers. comm.). While this shipping activity facilitates exchange of goods and products and stimulates regional and national economies, it also brings significant risk of ship strikes to whales.

Efforts to reduce population impacts of ship strikes in waters off central California were initiated in response to an Unusual Mortality Event (UME) that was designated by the National Oceanic and Atmospheric Administration when 5 blue whales were confirmed struck by ships and killed in coastal southern California in September 2007. Since then, important feeding areas for blue and humpback whales have been identified in waters adjacent to the ports of Long Beach/Los Angeles and San Francisco Bay where they intersect vessel traffic lanes, also known as Traffic Separation Schemes (TSSs) (Dransfield et al. 2014, Irvine et al. 2014, Calambokidis et al. 2015). The elevated co-occurrence between ships and whales in portions of the TSSs combined with the UME made these regions the focus of west coast ship-strike reduction efforts. Conservation efforts to decrease ship-strike mortality rates were initiated by establishing voluntary speed reduction programs (Freedman et al. 2017).
In 2013, the United States Coast Guard (USCG) and the International Maritime Organization (IMO) rerouted the TSS approaches to San Francisco Bay to increase mariner safety (Dransfield et al. 2014). They also took into account input from the national marine sanctuaries to avoid known whale feeding and aggregation areas in the new TSS design. Even with the resulting reduction in the overlap of important whale habitat and ship traffic, vessel strikes continued to occur, likely in part because the Northern and Western traffic lanes (see Fig. 1) still cross through key whale habitat (Rockwood et al. 2020).

In 2015, to further address ship strikes, Greater Farallones and Cordell Bank National Marine Sanctuaries (GFNMS and CBNMS; hereafter, Sanctuaries) implemented a seasonal fixed date (May 1 to November 15) voluntary Vessel Speed Reduction (VSR) requesting that ships of 300 gross registered tons or larger restrict speed to $10 \mathrm{kn}$ or less in all 3 outer shipping lanes (Northern, Western and Southern lanes). The Sanctuaries also implemented an evaluation and reporting program, by which shipping companies are sent letters quantifying their vessels' level of cooperation when transiting through the predetermined VSR zones. Additionally, in 2017, in an effort to increase cooperation with the VSR, the Bay Area Air Quality Management District began offering incentives that provided modest monetary payment and positive press to shipping companies for adhering to VSRs.

Voluntary cooperation from commercial vessels transiting within the TSS to and from the San Francisco Bay during the VSR has increased from $29 \%$ in 2015 to $45 \%$ in 2016, measured as the cumulative percentage of transits that are $10 \mathrm{kn}$ or below (M. Carver pers. comm.). This shift suggests that current outreach to shipping companies may be influencing the behavior of large vessel operators. However, the proportion of vessels cooperating with the VSR did not increase in 2017. As documented by recent research (Vanderlaan \& Taggart 2009, McKenna et al. 2012, Jensen et al. 2015, Moore et al. 2018), factors other than the VSR (e.g. delivery schedules, emissions regulations) also influence ship behavior. These and economic motivators of shipping company behavior mean there are likely limits to voluntary cooperation; mandatory regulations, on the other hand, have garnered high ship speed limit compliance in other places (McKenna et al. 2012, Freedman et al. 2017).

We used high-resolution $\left(1 \mathrm{~km}^{2}\right)$ whale habitat models of blue and humpback whales (Rockwood et al. 2020) to improve regional predictions of ship-strike 

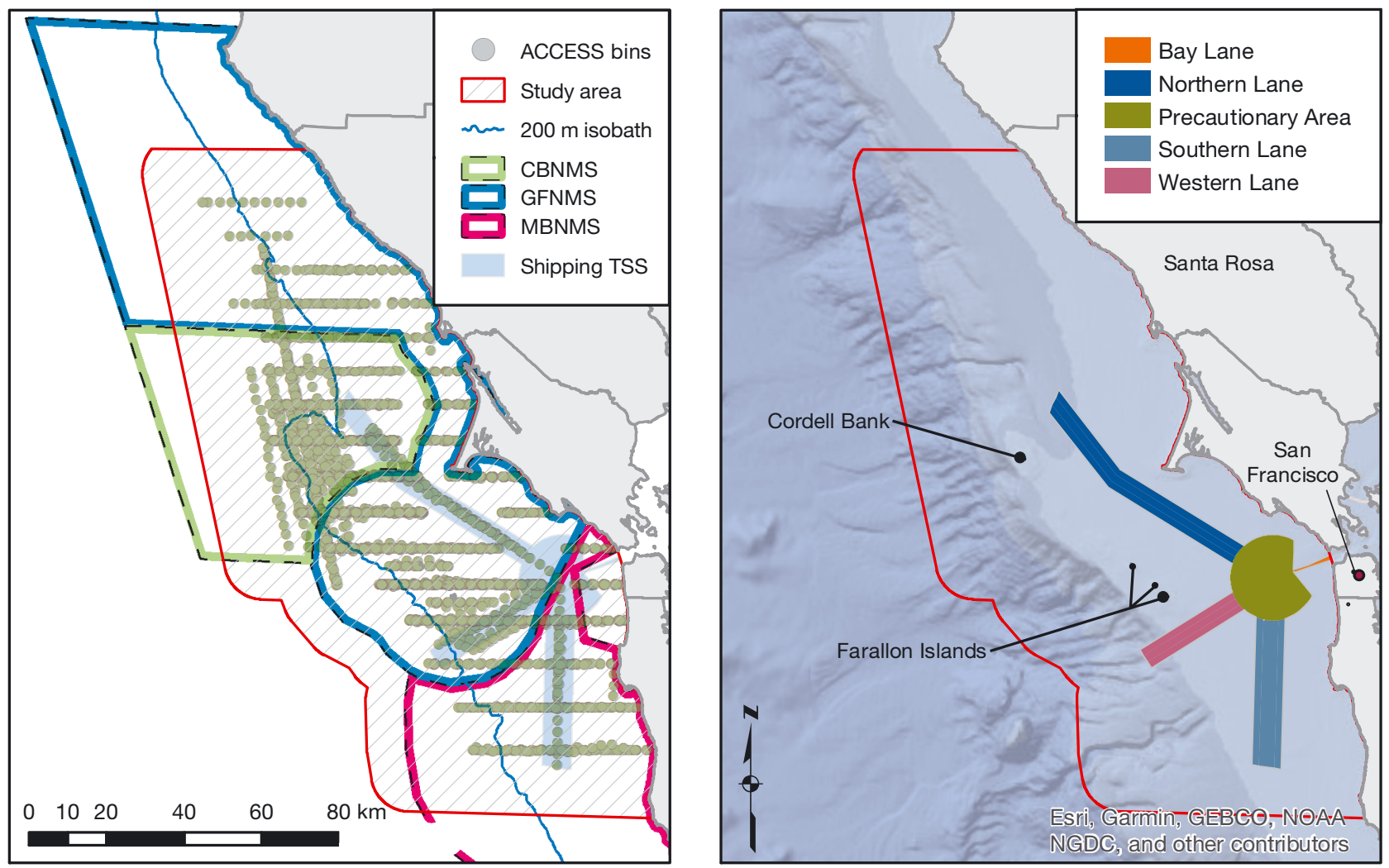

Fig. 1. Study area around the shipping approaches (TSS: Traffic Separation Scheme) to San Francisco Bay ports, including $200 \mathrm{~m}$ depth contour, sanctuary boundaries and sampling bins from the ACCESS cruises, landmarks and TSS lanes. CBNMS: Cordell Bank National Marine Sanctuary (NMS); GFNMS: Greater Farallones NMS; MBNMS: Monterey Bay NMS

mortality for approaches to San Francisco Bay ports and surrounding waters. We also performed a model assessment of the change in mortality attributable to vessel speed changes during the years when the VSR was in force. Finally, we modeled the hypothetical changes in whale mortality under a variety of VSR scenarios including speed limits of 12 or $10 \mathrm{kn}$ and cooperation levels ranging up to $95 \%$ cooperation. The results of this work are intended to assess total mortality along with spatial and temporal patterns of ship-strike risk in this region. Evaluation of how much the past VSR reduced mortality is vital to designing improvements to the VSR program. Predicting the effects of such future improvements can help decision-makers weigh trade-offs and determine how to decrease the deaths caused by ship collisions.

\section{MATERIALS AND METHODS}

\subsection{Study area}

The study area spans from Gualala, California in the north to Pescadero, California in the south and extends approximately 60 miles from the coast, covering a total of $12640 \mathrm{~km}^{2}$ and portions of Cordell Bank, Greater Farallon and Monterey Bay National Marine Sanctuaries (Fig. 1). Within the study area, Cordell Bank and the continental shelf margin (indicated by the $200 \mathrm{~m}$ isobaths) are particularly notable for high productivity and consistent feeding aggregations of baleen whales (Dransfield et al. 2014, Calambokidis et al. 2015, Rockwood et al. 2020). Three TSS lanes - Northern, Western and Southern - connect to a central precautionary zone and Bay lane which provide vessel entry and exit to ports within San Francisco Bay (Fig. 1).

We established a geographical grid within the study area which covers the region surveyed by the Applied California Current Ecosystem Studies (ACCESS) cruises (described in Section 2.2.). The grid resolution was $1 \mathrm{~km}^{2}$ (1 km by $\left.1 \mathrm{~km}\right)$ per cell, resulting in 12631 cells within the study area. Mortality for both species was modeled across the entire study area while pre/post VSR mortality comparisons were assessed only within the TSS. VSR scenarios were calculated within the TSS and 3 potential Seasonal Management Areas (SMAs) which we defined 
— polygon areas that contained the majority of highmortality predictions outside the TSS (see Fig. 7).

\subsection{Whale data}

Whale density for blue and humpback whales was sourced from model predictions based on line transect data collected by ACCESS (Rockwood et al. 2020). To briefly review the methods from Rockwood et al. (2020): Species distribution models were built using environmental predictors and fit to whale sightings from systematic boat-based line transect surveys conducted by the ACCESS program. Surveys were conducted in April to October from 2004 to 2017. Generalized linear models were determined through reverse variable selection, followed by comparison of model performance metrics (Akaike's information criterion [AIC], mean absolute error [MAE] and RMSE) and cross validation. Negative binomial models with log links were selected
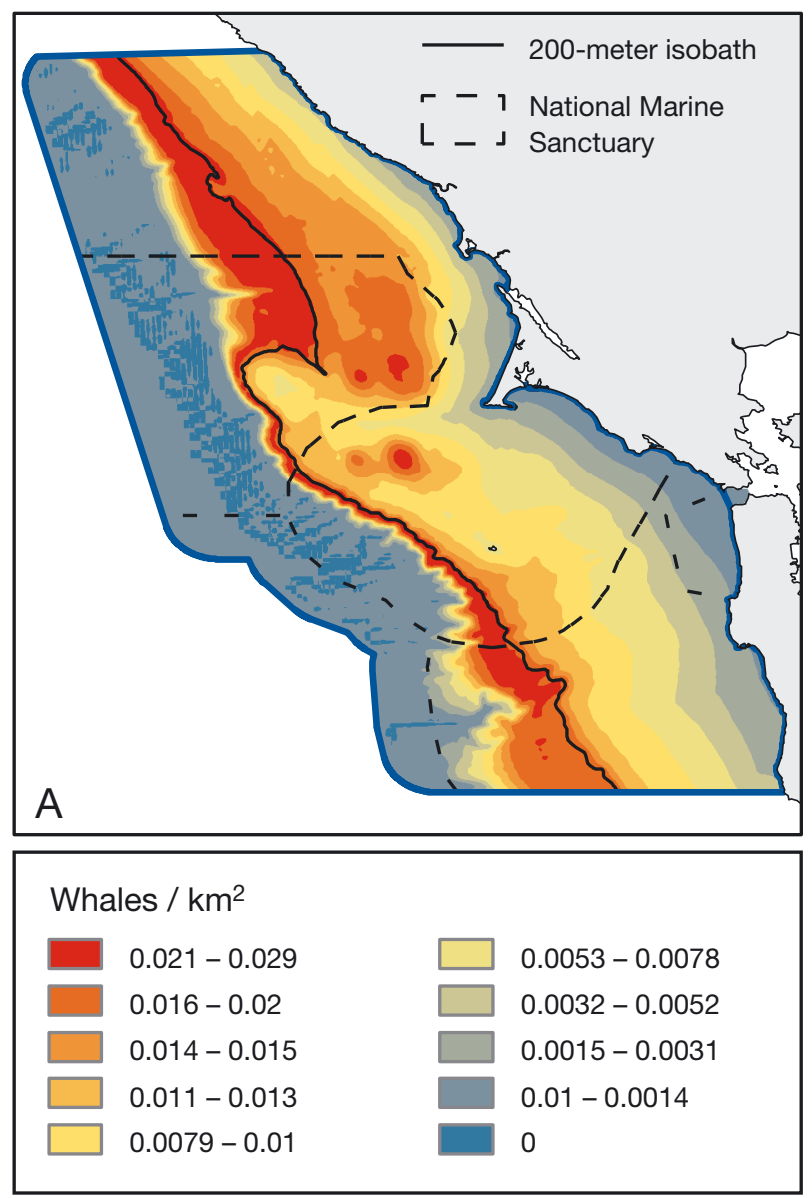

because of improved fits to the zero-inflated whale count data. For this study, we predicted whale density on the grid of $1 \mathrm{~km}$ resolution cells for May to July and September (the months with sufficient numbers of cruises for robust prediction) from 2012-2017. These predictions represent a snapshot count (not cumulative density over the month) based on average monthly cruise conditions. Density data for 2012-2017 matching the available vessel data were used for this study. Full details of the model building, selection and prediction methods can be found in Rockwood et al. (2020). We converted whale density to number of whales per grid cell by multiplying the modeled densities by the area of each grid cell (Fig. 2).

\subsection{Ship data}

Our strike model requires ship speed, draft, vessel count, transit time and track distance as inputs
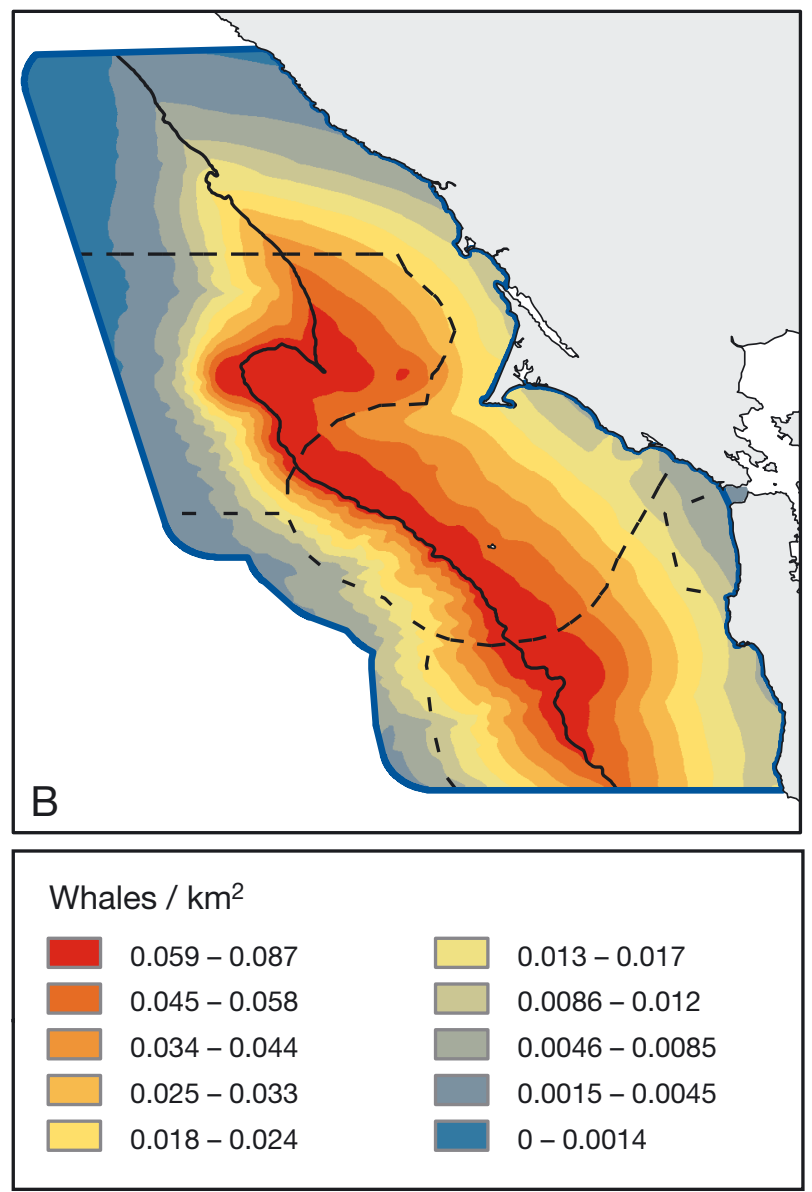

Fig. 2. Species distribution model density for blue whales (A) and humpback whales (B) averaged across all surveyed years and months from 2004-2017. Note the color scales are different for each species. Density predictions derived from ACCESS cruise data 
(Rockwood et al. 2017). We used Automated Identification System (AIS) records to provide this data. AIS is maritime safety technology intended to avoid atsea collisions and required in US waters for most vessels over $65 \mathrm{ft}(19.8 \mathrm{~m})$ and all vessels over 300 gross tons. AIS systems broadcast a vessel's movements and physical characteristics via very high frequency (VHF) radio signals. AIS messages containing position data (e.g. location, speed, heading) are broadcast every 2 to $10 \mathrm{~s}$ and messages with static vessel and voyage-related data (information provided about a vessel when AIS equipment is initialized, e.g. identifier, length, type) every $6 \mathrm{~min}$. AIS messages are also received by land-based stations and loworbiting satellites. The AIS data collected by these networks of receiving stations is used for a variety of applications beyond collision avoidance (Robards et al. 2016).

We obtained 5 years (2012-2017) of raw AIS data collected by the USCG's Nationwide Automatic Identification System (NAIS) network of land-based stations to conduct our analyses. We used the Department of Transportation's VOLPE Data Center's Transview (TV32) software application to decode the raw AIS data into comma separated value (CSV) files, which were stored and analyzed within a spatially enabled PostgreSQL/PostGIS database.

Vessels longer than $19 \mathrm{~m}$ accounted for the majority $(76 \%)$ of whale deaths in a database of strikes (Jensen \& Silber 2004). Even that proportion likely underestimates the contribution of larger vessels because smaller vessels are much more likely to feel and report a collision with a whale (Peel et al. 2018). In addition, only vessels larger than $65 \mathrm{ft}$ (19.8 m) are required to use AIS. We therefore filtered the AIS data to records associated with vessels greater than $19 \mathrm{~m}$ in length, with drafts of at least $2 \mathrm{~m}$. We generated vessel tracks by aggregating temporally proximate records belonging to unique vessels. Tracks were then clipped to our grid cells and the resulting track segments were assigned vessel attributes (speed, beam and draft) from the AIS record with the closest proximity. We also used the resulting line features to tabulate the track segment length and transit time through the cell. Because vessel characteristics provided in AIS transmissions are subject to transcription error and omission, we chose to include only those AIS messages whose vessel data could be cross-linked and verified in the IHS Maritime World Register of Ships (IHS), a comprehensive database housing ownership and ship characteristic data on the global merchant fleet. This filtration eliminates potential errors but is unlikely to remove entire ves- sel transits since it is improbable that all messages broadcast during a particular voyage would be similarly corrupted.

Vessel transit time can be determined either by dividing the reported vessel speed by the track distance or by finding the time elapsed between the estimated track entry and exit from the grid cell. For cases where the time elapsed between entry and exit was greater than $2 \mathrm{~h}$ (corresponding to a speed of less than $0.38 \mathrm{kn}$ for the longest straight-line transit through a cell), we calculated transit time as speed divided by distance. Similarly, if reported speeds were zero, negative or greater than $40 \mathrm{kn}$ (indicating the AIS message was faulty), we calculated speed as the distance traveled divided by the time of transit. Finally, to exclude erroneous records and vessels not under way, we eliminated remaining segments with speeds less than 2 or greater than $40 \mathrm{kn}$ and distances greater than $6 \mathrm{~km}$. This resulted in the culling of less than $1 \%$ of all data records (i.e. track segments) and less than $0.25 \%$ of the total vessel distance travelled.

We analyzed data from 2012-2017 to cover a control period prior to the full VSR implementation and a period with the VSR in place. However, it is important to note that this range of years is also divided into years prior to the TSS rerouting (2012-2013) and those after (2014-2017). Therefore, each type of analysis (annual mortality modeling, VSR effect modeling and scenario simulations) used particular temporal subsets to ensure data appropriate to the task. These timeframes are described in Section 2.6.

\subsection{Model framework}

To estimate mortality, we further improved the encounter theory-based model developed by Martin et al. (2016) and modified by Rockwood et al. (2017). Equations and model descriptions can be found in those publications. Encounter theory is used in naval warfare to determine the likelihood of contact with enemy vessels and has been applied in ecology to understand predator-prey dynamics as well as in statistical analysis of capture-recapture data (Gurarie \& Ovaskainen 2013, Martin et al. 2016, Crum et al. 2019). To briefly reiterate, our model used a 2dimensional geometrical formulation of encounter theory to calculate an encounter rate between a vessel and whale within each spatial grid cell. Encounter rate is a function of whale and vessel sizes, velocities, distance traveled and grid cell size. We used multisensor tag data to quantify whale time-at-depth 
(Rockwood et al. 2017), allowing us to integrate the effect of 3-dimensional habitat use by whales on the risk of being in the vertical strike zone. Here, as in Rockwood et al. (2017), the strike zone is conservatively defined as the draft of the vessel, though scale models suggest whales may be at risk up to twice the vessel draft (Silber et al. 2010). Finally, the probability of collision avoidance, of mortality given a collision and the densities of whales and ships enable conversion of encounter rates to estimates of whale mortality.

We made several changes to the model used by Rockwood et al. (2017) to improve performance and accuracy. First, since using a linear relationship between avoidance response with increasing vessel speed resulted in very similar mortality results as a logistic relationship (Rockwood et al. 2017), we chose to limit our analysis to only the logistic formulation of avoidance. Though the speed-avoidance relationship remains poorly characterized, observations and research have best supported the logistic formulation (Gende et al. 2011). In previous versions of this model (Rockwood et al. 2017), mean ship parameters were calculated across all vessels within a grid cell prior to running the mortality model. However, this approach has the potential to introduce bias due to the nonlinear relationships between strike mortality and some ship parameters, especially speed.

Thus, we modified the model approach here to calculate the estimated number of mortalities for each vessel track independently and then summed those estimates within each grid cell. Encounter rate, $\lambda_{e}$ was defined as:

$$
\lambda_{e}=\frac{2 r_{C}}{S} \int_{V_{m}} I\left(v_{m}, V_{b}\right) V_{m} \mathrm{~d} v_{m}
$$

where $r_{c}$ is the critical radius, $S$ is the cell area, $v_{m}$ is the whale velocity, $V_{b}$ is the vessel velocity, and $I\left(v_{m}\right.$, $V_{b}$ ) is an increasing function of the velocities as derived from encounter theory (Martin et al. 2016). This encounter rate does not account for destructive encounters (i.e. density decrease when strikes kill whales) but because the encounter rate is very low, reviews of encounter theory have found this effect to be small (Gurarie \& Ovaskainen 2013).

The mortality formulation for each grid cell is:

$$
\begin{gathered}
\text { Mortality }=\sum_{b=1}^{n} \lambda_{e b} t_{b} P\left(\text { Strike depth } \mid D_{b}\right) \\
{\left[1-P\left(\text { Avoidance } \mid V_{b}\right)\right] P\left(\text { Mortality } \mid v_{b}\right) N_{m}}
\end{gathered}
$$

where $b$ is the vessel track identifier, $n$ is the number of tracks in the grid cell, $\lambda_{e b}$ is the encounter rate, $t_{b}$ is the vessel's transit time, $P\left(\right.$ Strike depth $\left.\mid D_{b}\right)$ is the probability the whale is within the vessel strike depth given the vessel draft, (1-P(Avoidance $\left(v_{b}\right)$ ) is the probability of no successful avoidance given the vessel's speed, $P\left(\right.$ Mortality $\left.\mid V_{b}\right)$ is the probability of mortality given the vessels speed, and $N_{m}$ is the number of whales in the grid cell. $P$ (Mortality $\left.\mid v_{b}\right)$ is calculated according to Conn \& Silber (2013), based on the vessel speed during the specific track segment.

This model was applied to each grid cell for each month and species combination. Monthly results were summed to create spatially explicit predictions of mortality for the 4 months included in the study and for each year from 2012 through 2017. It is important to note that since we do not estimate mortality for August or for months when relatively few whales are present (October to April) in this region, our summed mortalities should be considered as underestimates. However, we chose not to extrapolate or interpolate our models to unsampled months because of the error that would result from seasonal and interannual variability in the spatial distribution of whales. All modeling and statistical calculations were done in the programming language $\mathrm{R}$ 3.6.1 (R Core Team 2019), while all maps were produced using ArcGIS 10.5.

\subsection{Spatial statistics within management jurisdictions}

A key goal of this research was to understand whale mortality resulting from ship strikes and explore the potential for new management actions. To this end, we defined 2 classes of notable predicted mortality: pixels with predictions above (1) the 50th and (2) the 90th percentiles. We converted these areas to polygons and mapped them for visual assessment. We only used results from 2014-2017 for these spatial analyses because of the 2013 TSS changes.

To estimate mortality in relevant jurisdictions, we calculated the sum of mortality and proportion of total mortality within the TSS, the Sanctuaries and the BIAs defined by Calambokidis et al. (2015). TSS results are reported in the manuscript, while results for other areas are provided in the Supplement at www.int-res.com/articles/suppl/n043p145_supp.pdf (Fig. S1, Tables S1, S2 \& S3). TSS polygons were produced by the NOAA Office of Coast Survey (downloaded from https://catalog.data.gov/dataset/shippingfairways-lanes-and-zones-for-us-waters44831). For 
each jurisdiction, we calculated the total mortality, mortality per $100000 \mathrm{~km}^{2}$ and the proportion of total mortality. Mortality per area provides a measure of the 'intensity' of risk, while proportion of total mortality provides a gauge of the relative importance of vessel strikes within the given area.

\subsection{Speed changes and VSR effect on mortality}

To assess the effect the VSR had on the amount of whale mortality, times with the VSR in place cannot simply be compared to times without VSR implementation because there are multiple confounding factors. These include potential changes in ship traffic spatial patterns, vessel sizes, and whale density and distribution. To control for these, we used a simulation approach where vessel speeds from times outside the VSR implementation were re-sampled and applied to vessel tracks for times during the VSR. Model mortality was then calculated within the shipping lanes for the true speeds for the 2015-2017 periods when VSR were employed (VSR 'reference' model mortality) and for the speeds resampled from non-VSR periods ('simulated' model mortality). All other model variables (e.g. vessel drafts, vessel beam, whale density) were kept consistent. The differences between VSR 'reference' and 'simulated' model mortalities (calculated for each of the 3 years 2015-2017) estimate the effect of speed changes between VSR and non-VSR periods.

We used 2 time periods as controls: years prior to the VSR (2012-2014; henceforth 'pre-VSR' period) or months outside of the VSR period (January 1 to April 30 and November 16 to December 31; henceforth 'inactive-VSR' period) but within the same years. Because there has been a long-term downward trend in vessel speeds (Moore et al. 2018), it is impossible to unequivocally attribute speed changes (and therefore mortality changes) between 2012-2014 (preVSR) and 2015-2017 (active-VSR) to the VSR specifically. Similarly, the potential for seasonal speed patterns (McKenna et al. 2012, Jensen et al. 2015) could influence within-year comparison of activeand inactive-VSR periods. Therefore, we used both pre-VSR/active-VSR VSR simulation (applying 20122014 pre-VSR speeds to 2015-2017) and inactive/ active simulation (applying January 1 to April 30 and November 16 to December 31 speeds to May 1 to November 15 of each year) as the temporal controls to assess the relative effect of VSRs on whale mortality. We expected the inactive/active simulation to best isolate the VSR-specific effect, but were also interested in the inter-annual trend in modeled mortality due to changes in speed regardless of whether the changes were entirely a result of vessels adhering to an established VSR.

To account for spatial patterns in speed, we pooled all speeds across non-VSR years (for the pre/post analysis) and across non-VSR months (for the inactive/ active analysis), but only resampled speeds within the same grid cell. For each VSR year, we generated 100 random samples (with replacement) and replaced the speed attribute of the ship track lines. For each sample, we calculated the 'simulated speed' mortality. To understand the effect the resampling process had on the results, we also calculated the standard deviation for each year's 'simulated speed' mortality estimates.

Finally, to determine the spatial pattern of change in risk of mortality, we subtracted the resulting raster of active-VSR mortality from both the pre-VSR and inactive-VSR rasters for each year 2015 to 2017. Maps of this difference show where estimated mortality decreased or increased between control periods (no VSR) and active-VSR periods (see Figs. 9 $\& 10)$.

\subsection{Assessing management scenarios}

Predicting the effect of current and possible future management scenarios is necessary to determine how effective management could be at decreasing mortality. Models were therefore applied to areas consisting of existing TSSs and 3 hypothetical SMAs to simulate expected whale mortality rates under various scenarios. Hypothetical SMAs, involving speed restrictions of both 10 and $12 \mathrm{kn}$ were positioned at the end of each leg of existing TSSs (see Fig. 7) to encompass areas identified as the highest mortality areas outside the TSS.

Currently, the VSR in the study region is set at $10 \mathrm{kn}$. However, other locations have used a $12 \mathrm{kn}$ limit and industry has argued that the $12 \mathrm{kn}$ speed enhances maneuverability and vessel safety (Abramson et al. 2010). Thus, determining the influence of these alternate speed limits on mortality is informative for management. In addition, while vessel VSR cooperation increased for the first 2 years of the VSR in our study area, the trend did not continue in 2017. Other studies have documented a lack of cooperation with voluntary measures (Wiley et al. 2008, Silber et al. 2012a, Freedman et al. 2017). In contrast, significant increases in compliance were seen after right whale protections on the east coast 
were made mandatory (Lagueux et al. 2011, Silber et al. 2014). Thus, to inform management strategies we explored the results of higher cooperation levels consistent with mandatory speed limits.

For each month, we simulated cooperation scenarios ranging from 30 to $95 \%$ cooperation with both 10 and $12 \mathrm{kn}$ speed limits. These values were selected to include ranges observed prior to establishing VSRs in our study area and compliance levels with VSRs observed in right whale SMAs established at port approaches along the US east coast (Lagueux et al. 2011, Silber et al. 2014). For each month, we calculated the proportion of distance traveled at or below the relevant speed limit. Then, we calculated the additional proportion of track lines that would need to slow to the speed limit to achieve the target cooperation level. For example, if the actual cooperation was $28 \%$ and the target was $40 \%$, an additional $12 \%$ of tracks would need to travel at the speed limit. We randomly selected that proportion of tracks and set their speed to the prescribed limit. To be as realistic as possible, we chose to modify speeds at set limits for the entire transit rather than a random selection of gridclipped track segments. To assess the influence of the resampling on mortality estimates, we repeated the sampling process 100 times and calculated the coefficient of variation (CV) for the results. To maintain relevance to current traffic patterns, we only used the years after the TSS rerouting (2014-2017) in this analysis.

We then averaged across the 100 resampled estimates to get a single mortality estimate for each combination of month, speed and level of cooperation. These estimates were compared to the 'VSR speed' model mortality estimated using actual vessel speeds. This provided an estimated decrease in the number of whale deaths due to the simulated increase in vessel operator adherence with the measure. To determine the change in mortality caused by a proportional increase in cooperation for each species, we fitted linear models to each year and speed combination.

\section{RESULTS}

We report summary values and synoptic spatial patterns because averaging across time helps minimize uncertainty and variability inherent in whale densities and spatial distribution models. For context and to evaluate the importance of the fine-scale assessments described here, we compare our results to those from Rockwood et al. (2017). To make results comparable, the Rockwood et al. (2017) results have been re-calculated for season and areas assessed here. For simplicity, we refer to the model results as 'mortality' and 'strike intensity' (deaths per $10^{5} \mathrm{~km}^{2}$ ), but it is important to reiterate that all results represent modeled estimates of ship strikes, not observed whale mortalities. Strike intensity allows areas of different sizes to be easily compared and is normalized to an area of $10^{5} \mathrm{~km}^{2}$, chosen so that results are not small decimals.

We emphasize that uncertainty in this modeling approach means that specific mortalities reported are only estimates. Each portion of the model has been formulated to be conservative (under-estimate mortality), but some model parameters (e.g. avoidance behavior of whales) have uncaptured uncertainty.

\subsection{Patterns of study area mortality}

The average of 2012-2017 estimated mortality for May to July and September for the entire study area was 2.7 blue whales and 7.0 humpback whales (Table 1). These estimates are 1.3 and 1.9 deaths higher than the corresponding estimates from Rockwood et al. (2017) and, for blue whales, exceed PBR in our study area alone.

The model suggests a steadily increasing total number of mortalities for humpback whales beginning in 2013 (Fig. 3). In contrast, expected blue whale mortality rates fluctuated annually with a peak in 2016 but no clear long-term trend. The temporal patterns of estimated mortality rates closely corresponded to temporal patterns of modeled local abundances for each species.

Spatial patterns showed the greatest mortality along the shelf break, especially in the Western lane, but expected deaths were more broadly dis- 


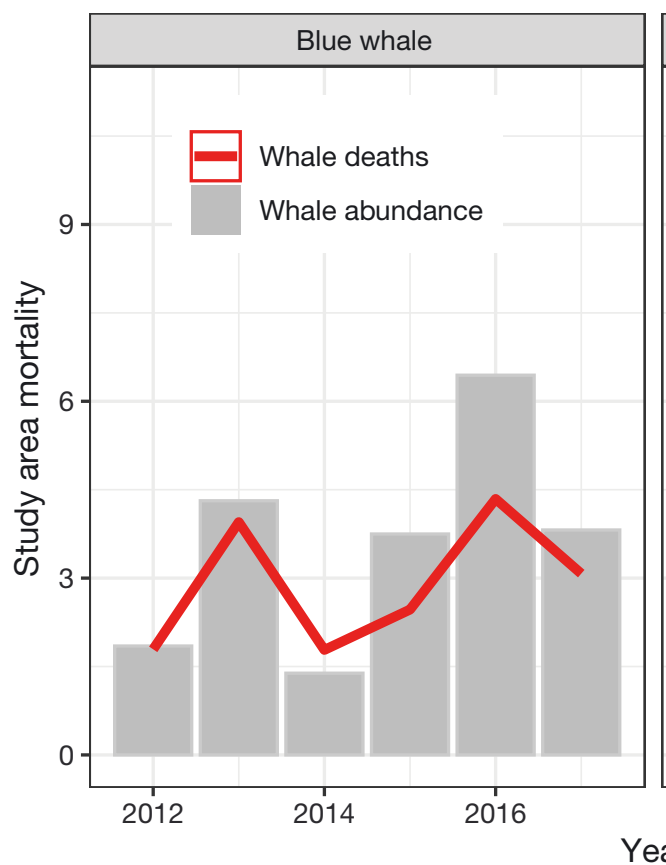

tributed closer to the coast for humpback whales as compared to blue whales (Fig. 4). Risk is highest in designated TSSs, but areas of high predicted mortality also extend beyond the ends of all routes, particularly the Northern and Western lanes. Most

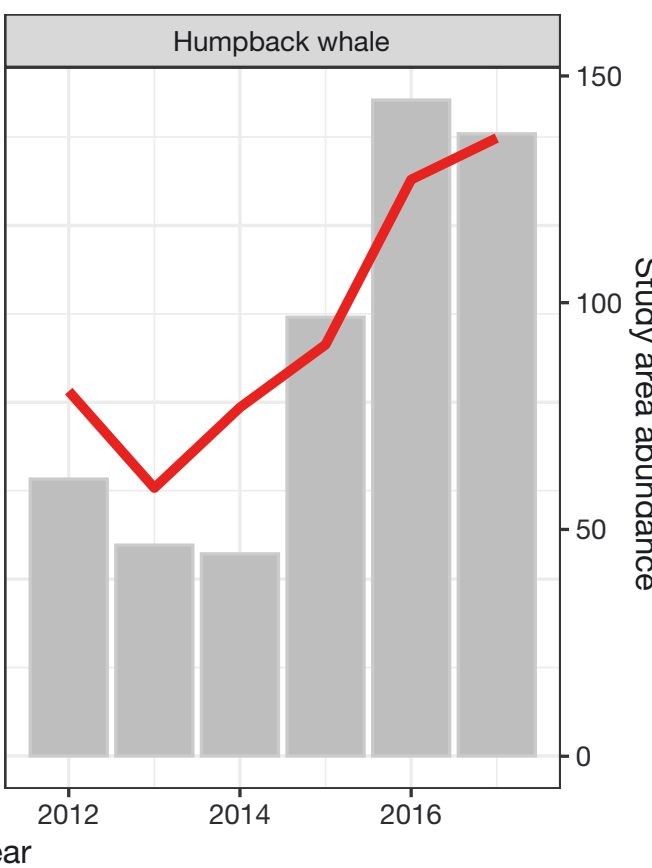

Fig. 3. Modeled output for estimated whale shipstrike mortality for the 4 month period each year of the study (2012-2017) and corresponding study area whale abundances. Note the different $y$-axis scales for mortality (left axis) and abundance (right axis) of the precautionary zone (where all lanes come together) shows lower mortality compared to adjacent areas, even for humpback whales, despite ship density being combined in this region from all lanes.

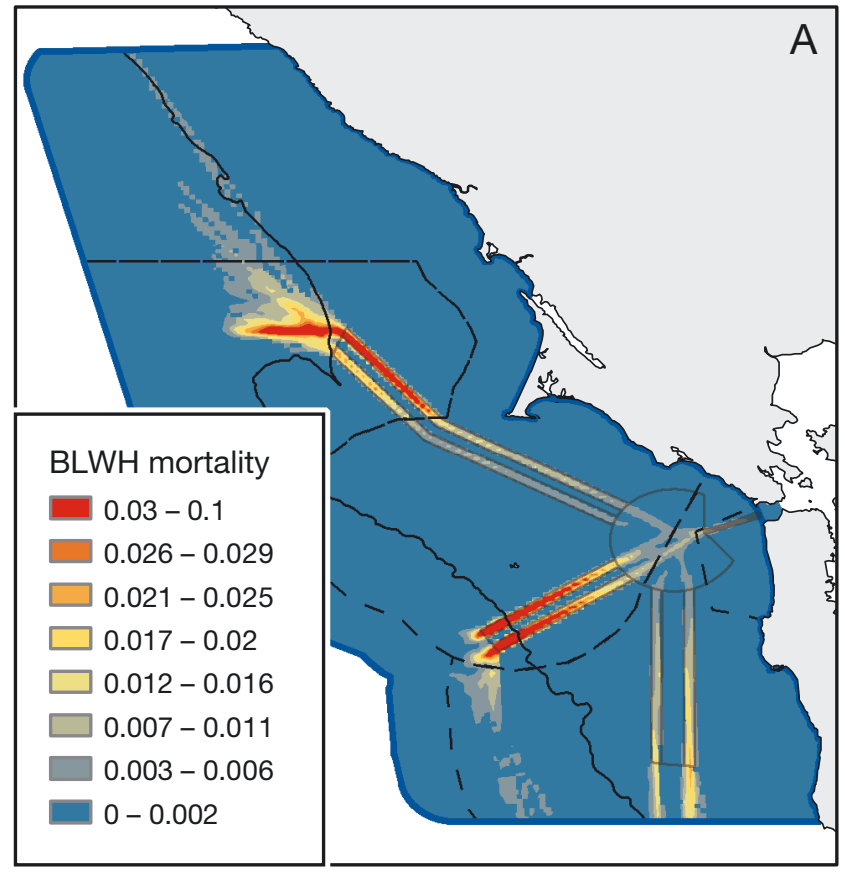

I_ _

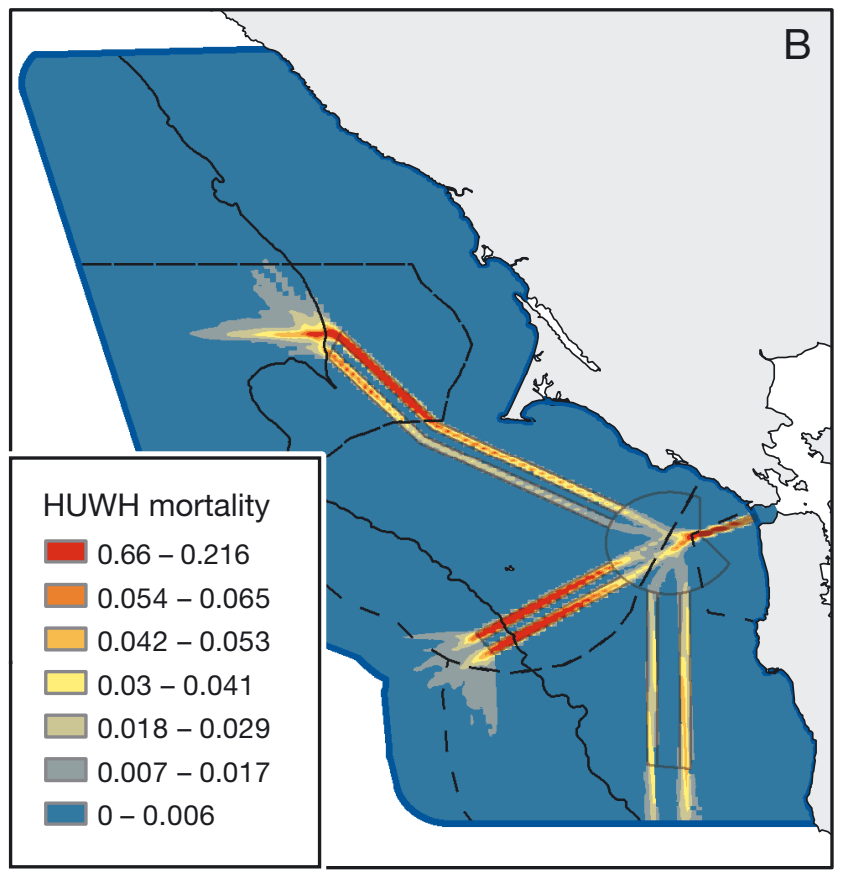

$200 \mathrm{~m}$ isobath
TSS

Fig. 4. Distribution of mean (A) blue (BLWH) and (B) humpback (HUWH) whale predicted mortality averaged across all surveys. Warmer colors represent higher mortality and each color is half a standard deviation except the highest range. Note the different scales for the 2 panels. Values are predicted mortalities per $1 \mathrm{~km}^{2}$ grid cell. TSS: Traffic Separation Scheme. For shipping lane details see Fig. 1 

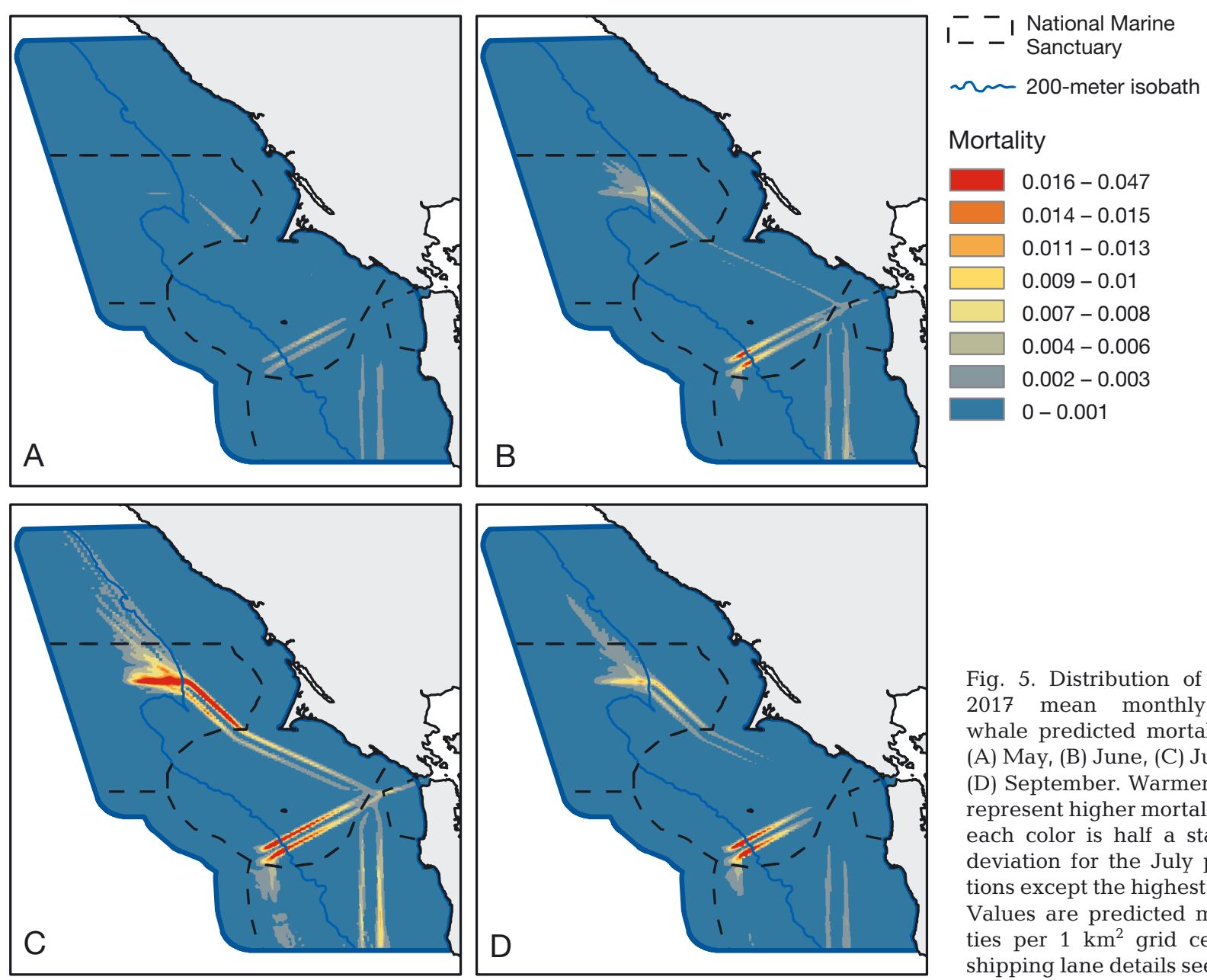

Fig. 5. Distribution of 20122017 mean monthly blue whale predicted mortality for (A) May, (B) June, (C) July and (D) September. Warmer colors represent higher mortality and each color is half a standard deviation for the July predictions except the highest range. Values are predicted mortalities per $1 \mathrm{~km}^{2}$ grid cell. For shipping lane details see Fig. 1

Spatial patterns of estimated monthly mortality highlight the concentration of risk at the shelf edge for blue whales (Fig. 5) compared to the broader distribution of humpback whale risk (Fig. 6). Blue whale risk showed a clear temporal peak in July, while risk was lowest in May and concentrated further from shore in May and September. The Western lane consistently exhibited the highest estimated risk across all months. Risk in the Northern lane was highest in July and September and the Southern lane risk peaked in July.

High humpback whale model mortality persists longer than for blue whales, consistent with their longer presence in the area and a later peak in abundance (Fossette et al. 2017, Rockwood et al. 2020). A period of high modeled mortality in May within the outbound Northern lane is likely driven by the use of this area by humpback whales early in the feeding season.

The regions of highest estimated mortality (50th and 90th percentile predictions) show similar pat- terns for both species, with 90th percentile areas concentrated in the offshore ends of the lanes (Fig. 7). For blue whales, areas of high modeled mortality extended north where northbound vessels travel across and along the shelf break. In comparison, humpback whales have higher risk through the precautionary zone and the Bay lane where especially dense traffic overlaps with inshore humpback whale distributions.

The 50th percentile area comprised over 98 and $95 \%$ of mortality for blue and humpback whales, respectively (Table 2). Large portions of the 50th and 90th percentile areas extend beyond the ends of the lanes, particularly the Northern and Western lanes (Fig. 7). We defined potential SMAs (green polygons in Fig. 7) to include most of the high-mortality areas outside the TSSs.

As measures aimed at minimizing the number of strikes have been focused solely in the shipping lanes, we also wanted to specifically compare expected mortality rates within the TSS with those outside 

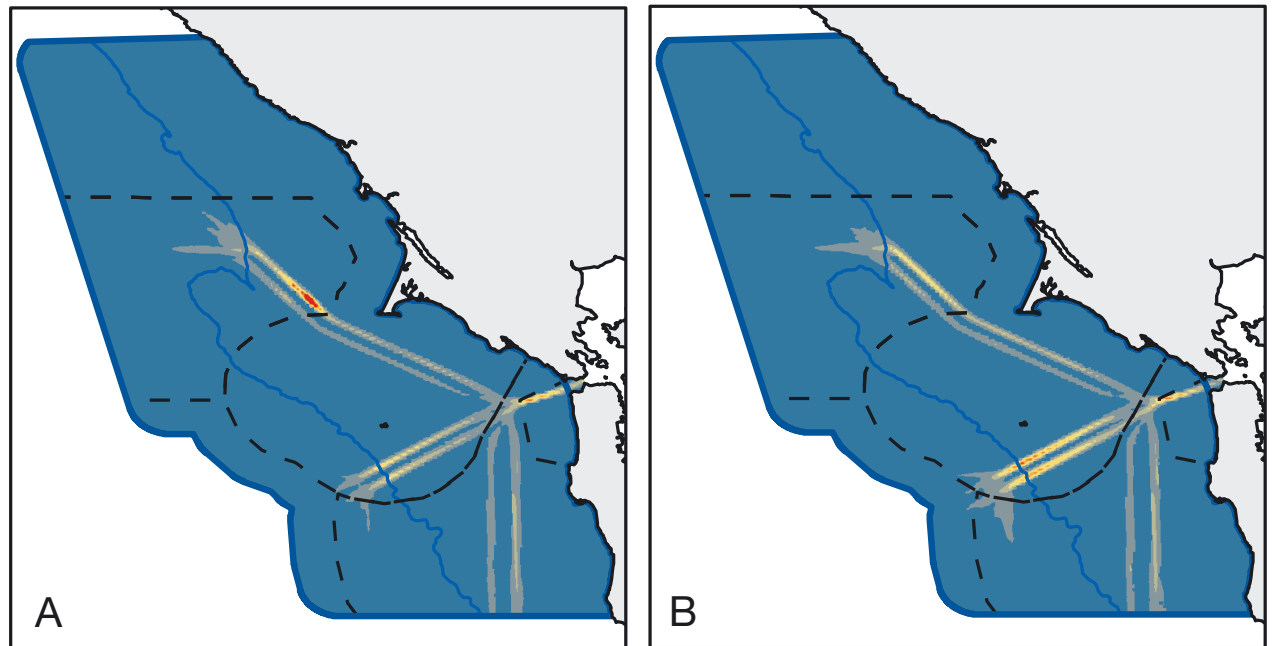

$$
\begin{aligned}
& \text { I_ I National Marine } \\
& \sim \text { 200-meter isobath }
\end{aligned}
$$

\section{Mortality}
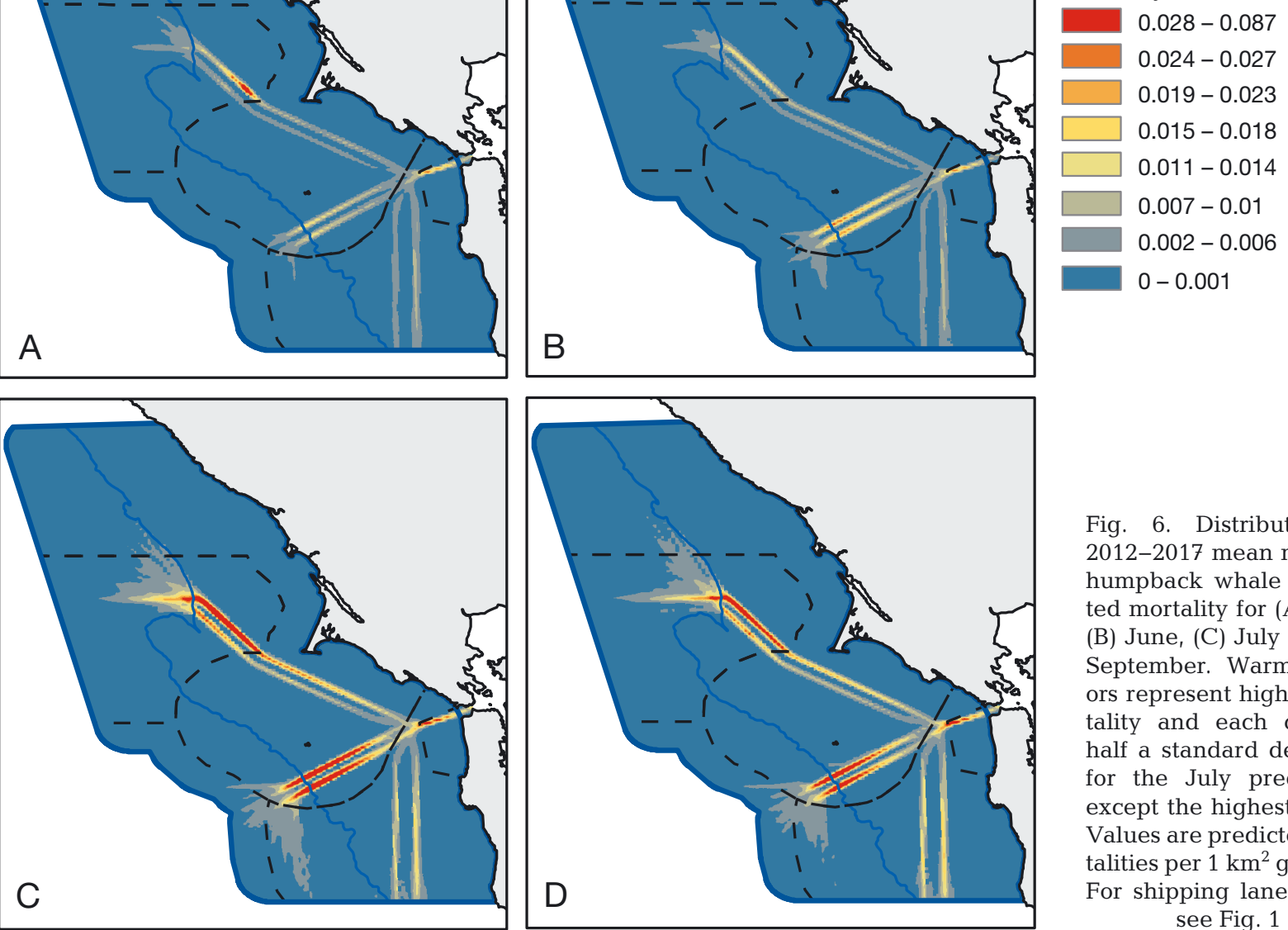

Fig. 6. Distribution of 2012-2017 mean monthly humpback whale predicted mortality for (A) May, (B) June, (C) July and (D) September. Warmer colors represent higher mortality and each color is half a standard deviation for the July predictions except the highest range. Values are predicted mortalities per $1 \mathrm{~km}^{2}$ grid cell. For shipping lane details see Fig. 1
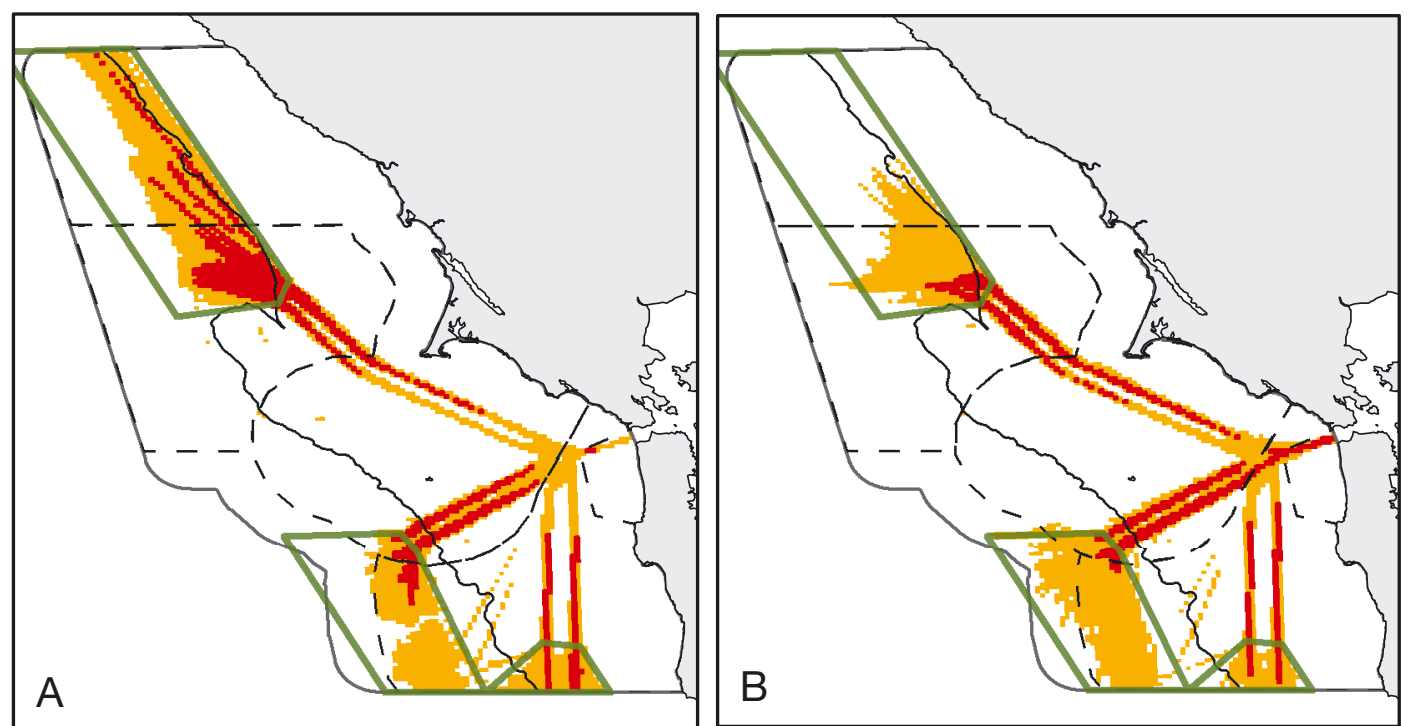

Proposed SMA

I_ I National Marine Sanctuary

$\sim 200 \mathrm{~m}$ isobath

50th percentile area

90th percentile area

Fig. 7. Areas classified as greater than the study area 50th and 90th percentile. Panels depict predicted whale mortality for (A) blue and (B) humpback whales. SMA: Seasonal Management 
Table 2. Percent of predicted mortality that falls within the 50th percentile and 90th percentile areas. Proportions are calculated on the mean of predicted mortality across 2013-2017

\begin{tabular}{|lcc|}
\hline Species & $\begin{array}{c}\text { Mortality within } \\
\text { 50th percentile } \\
\text { area (\%) }\end{array}$ & $\begin{array}{c}\text { Mortality within } \\
\text { 90th percentile } \\
\text { area (\%) }\end{array}$ \\
\hline Blue whale & 98.6 & 59.1 \\
Humpback whale & 95.7 & 58.6 \\
\hline
\end{tabular}

(Table 3). The model indicated that $47 \%$ of blue whale mortality would occur within TSSs compared to $53 \%$ outside TSSs. In contrast, $65 \%$ of humpback whale mortality was predicted to occur in TSSs and $36 \%$ outside them.

\subsection{Historical effect of VSRs and speed changes on mortality}

For 2015-2017 (the years with VSR in place), we simulated mortality using pre-VSR speeds (from 2012-2014; the pre-VSR control period) to assess the effect of reduced speeds on mortality rates, while keeping all other variables of our mortality model constant. Among pre-VSR years, 2013 had the lowest mean speed $(12.08 \mathrm{kn})$ and 2014 the highest (12.46 kn), with 2012 averaging $12.28 \mathrm{kn}$ (Fig. 8). We concluded that 2012-2014 showed no evidence of the long-term speed decline reported by Moore et al. (2018); therefore, it was reasonable to pool speeds across these years as a control period.

During pre-VSR years, a greater proportion of vessels traveled under $10 \mathrm{kn}$ during January to April and

Table 3. Estimated mortality statistics comparing areas inside of the Traffic Separation Scheme (TSS) to areas outside for blue (BLWH) and humpback (HUWH) whales. Mortality per $100000 \mathrm{~km}^{2}$ is an area-weighted metric to allow comparison between the different sized areas

\begin{tabular}{|c|c|c|c|c|c|c|c|}
\hline \multirow[t]{2}{*}{ Area } & \multirow{2}{*}{$\begin{array}{l}\text { Area } \\
\left(\mathrm{km}^{2}\right)\end{array}$} & \multicolumn{3}{|c|}{- BLWH 4 month mean -} & \multicolumn{3}{|c|}{- HUWH 4 month mean } \\
\hline & & Mortality & $\begin{array}{c}\text { Mortality } \\
\text { per } 10^{5} \mathrm{~km}^{2}\end{array}$ & $\begin{array}{l}\text { Percent of } \\
\text { total mortality }\end{array}$ & Mortality & $\begin{array}{c}\text { Mortality } \\
\text { per } 10^{5} \mathrm{~km}^{2}\end{array}$ & $\begin{array}{l}\text { Percent of } \\
\text { total mortality }\end{array}$ \\
\hline Within TSS & 1136 & 1.3 & 112 & 47 & 4.5 & 397 & 65 \\
\hline Outside TSS & 11509 & 1.4 & 12 & 53 & 2.5 & 22 & 36 \\
\hline
\end{tabular}

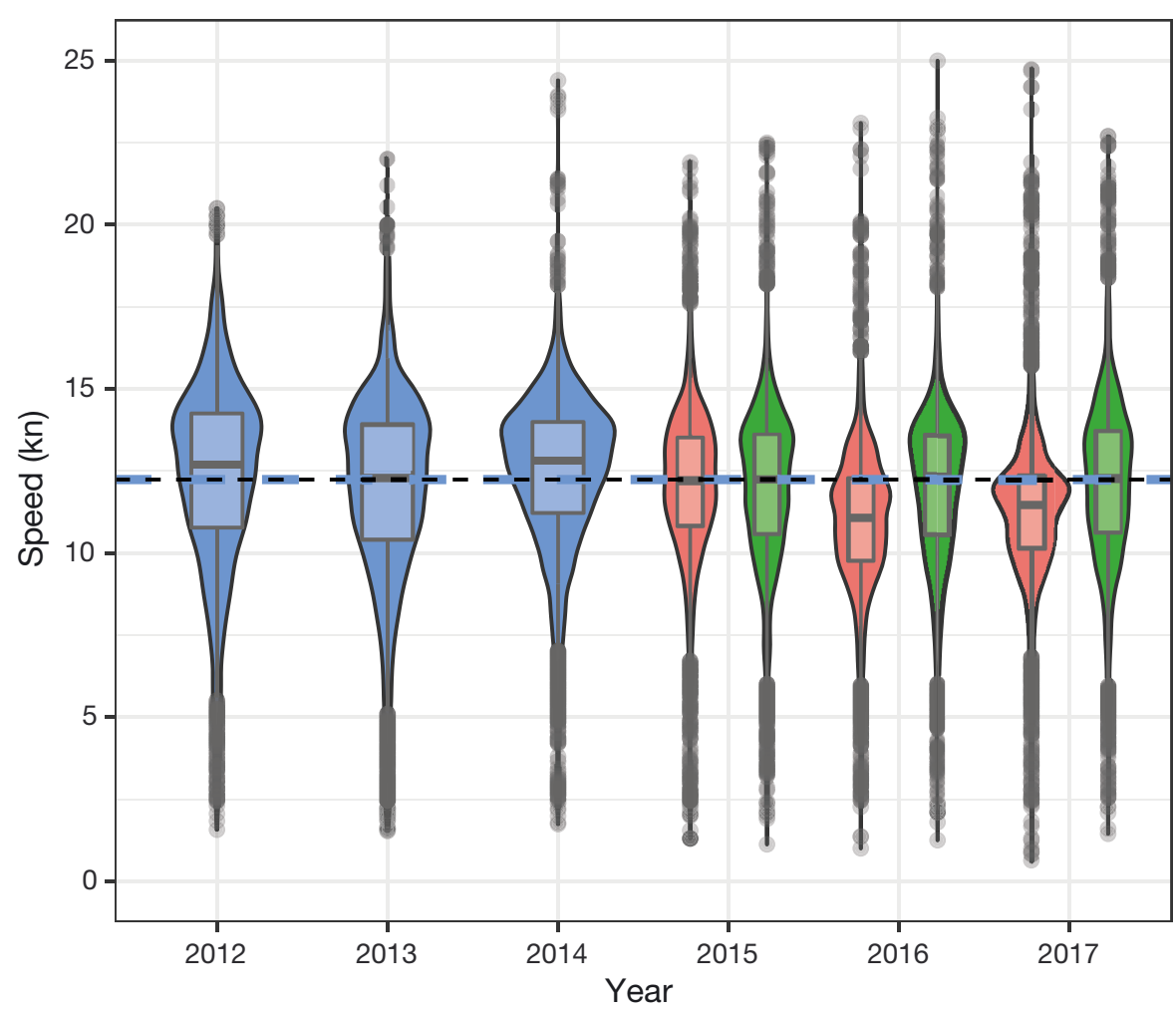

\section{VSR Period}

Active-VSR

Inactive-VSR

Pre-VSR
Fig. 8. Distributions of vessel speeds within the Traffic Separation Scheme (TSS) for 2012-2017. The width of the filled region is proportional to the number of values, the central grey line marks the median and outliers are plotted as grey dots. Active Vessel Speed Reduction (VSR) periods are May to July and September, and inactive VSR periods are January to April and November to December. Black and blue dashed line: pre-VSR mean speed 
Table 4. Percent change in number of vessels traveling under 10 and $12 \mathrm{kn}$ during active VSRs (May to July and September 2015-2017) compared to corresponding pre-VSR periods and inactive VSR periods. Change from pre-VSR is relative to the mean percent of vessels across May to July and September 2012-2014. Change from inactive periods (January to April and

November to December 2015-2017) is the difference within each year

\begin{tabular}{|c|c|c|c|c|}
\hline \multirow[t]{2}{*}{ Year } & \multicolumn{2}{|c|}{ No. of vessels traveling under $10 \mathrm{kn}-$} & \multicolumn{2}{|c|}{- No. of vessels traveling under $12 \mathrm{kn}$} \\
\hline & $\%$ change vs. Pre-VSR & $\%$ change vs. Inactive-VSR & $\%$ change vs. Pre-VSR & $\%$ change vs. Inactive-VSR \\
\hline 2015 & 3.0 & -1.7 & 6.0 & -0.9 \\
\hline 2016 & 17.1 & 14.8 & 16.6 & 11.8 \\
\hline 2017 & 14.2 & 10.9 & 17.5 & 12.4 \\
\hline
\end{tabular}

Table 5. Reference (active-VSR mortality) and simulated (pre-VSR and inactive-VSR) blue whale model mortality in all shipping lanes for 2015-2017. Percent mortality change is the percent difference between reference and each simulated speed mortality result

\begin{tabular}{cccccc} 
Year & $\begin{array}{c}\text { Pre-VSR } \\
\text { simulation } \\
\text { mortality }\end{array}$ & $\begin{array}{c}\text { Inactive-VSR } \\
\text { simulation } \\
\text { mortality }\end{array}$ & $\begin{array}{c}\text { Active-VSR } \\
\text { reference } \\
\text { mortality }\end{array}$ & $\begin{array}{c}\text { Percent mortality change } \\
\text { Pre-VSR } \\
\text { to active }\end{array}$ & $\begin{array}{c}\text { Inactive-VSR } \\
\text { to active }\end{array}$ \\
\hline 2015 & 0.85 & 0.80 & 0.86 & 1.9 & 7.7 \\
2016 & 2.49 & 2.36 & 2.20 & -13.0 & -7.3 \\
2017 & 2.17 & 2.05 & 1.96 & -10.6 & -4.8 \\
\hline
\end{tabular}

Table 6. Reference (active-VSR mortality) and simulated (pre-VSR and inactive-VSR) humpback whale model mortality in all shipping lanes for 20152017. Percent mortality change is the percent difference between reference and each simulated speed mortality result

\begin{tabular}{|cccccc|}
\hline Year & $\begin{array}{c}\text { Pre-VSR } \\
\text { simulation } \\
\text { mortality }\end{array}$ & $\begin{array}{c}\text { Inactive-VSR } \\
\text { simulation } \\
\text { mortality }\end{array}$ & $\begin{array}{c}\text { Active-VSR } \\
\text { reference } \\
\text { mortality }\end{array}$ & $\begin{array}{c}\text { Percent mortality change } \\
\text { Pre-VSR } \\
\text { to active }\end{array}$ & $\begin{array}{c}\text { Inactive-VSR } \\
\text { to active }\end{array}$ \\
\hline 2015 & 5.11 & 4.83 & 5.27 & 3.1 & 8.3 \\
2016 & 8.30 & 7.89 & 7.54 & -10.1 & -4.6 \\
2017 & 9.40 & 8.93 & 8.65 & -8.7 & -3.3 \\
\hline
\end{tabular}

November to December than in May to July and September (Table 4), suggesting season may influence vessel speeds. The same pattern continued in 2015 but reversed in 2016 and 2017 after a full year of VSR. The proportion of vessels traveling under $10 \mathrm{kn}$ increased by $3 \%$ in 2015 relative to pre-VSR levels, though it actually fell $1.7 \%$ relative to the inactive VSR months of 2015 (Table 4). In 2016 and 2017, 14.8 and $10.9 \%$ more vessels, respectively, traveled under $10 \mathrm{kn}$ during active than inactive-VSR months. These differences were less than the changes between 2016 and 2017 active-VSR months and pre-VSR years (17.1 and $14.2 \%$, respectively).

Reference mortality (mortality modeled from actual speeds during VSR time periods) for both species was slightly lower than simulated inactive-VSR mor- tality and slightly higher than simulated pre-VSR mortality in 2015, the first year of the VSR (Tables 5 \& 6). Significant decreases in predicted mortality were seen in 2016 and 2017 for both species (Tables $5 \& 6$ ) as a result of lower vessel speeds (Fig. 8) in those years. Overall, the predicted decreases in modeled mortality due to changes in speeds used from the 2012-2014 period to 2015-2017 are relatively small in absolute terms (less than 0.1 whale deaths per 4 month period for blue whales and less than 0.5 per 4 month period for humpback whales). Percent declines in predicted mortality were slightly greater for blue whales than humpback whales.

Spatial patterns of differences between control period (simulated nonVSR) mortality and reference mortality show the greatest change in the Bay lane (Figs. 9 \& 10). Declines in mortality predicted in 2016 and 2017 were indicated in the outbound Northern lane, both Western lanes and the incoming Southern lane. On the other hand, mortality increased under VSR for a portion of the precautionary zone and the Bay lanes in all years and especially between the inactive and active VSR predictions and for humpback whales (Figs. $9 \& 10$ ).

\subsection{VSR speed and cooperation scenarios}

The goal of the scenario modeling was to understand potential decreases in mortality achievable through future management in the San Francisco TSS or high predicted mortality areas outside the TSS like the potential SMAs we defined. We found that the reduction in mortality was linearly propor- 

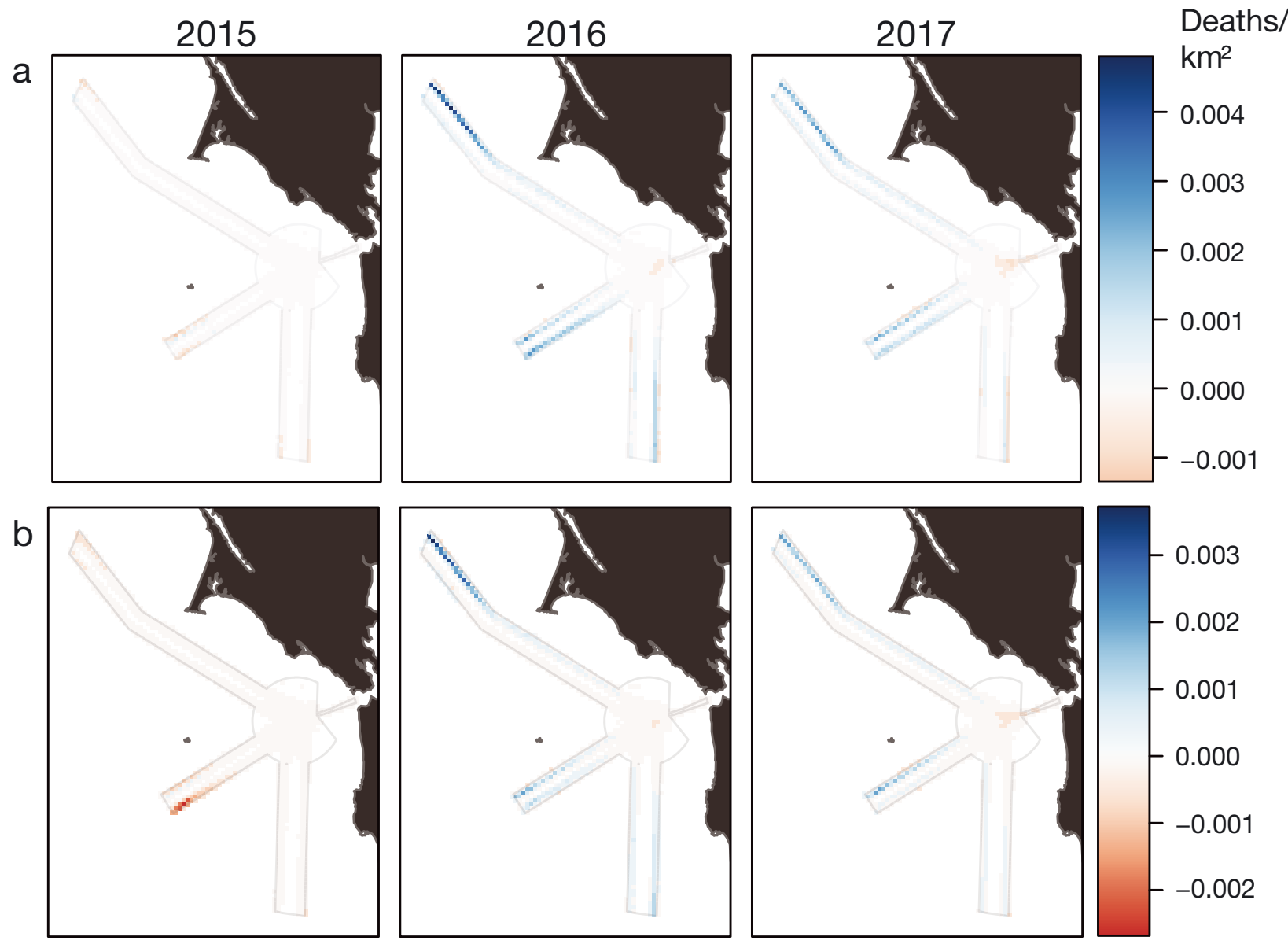

Fig. 9. Difference between mortality calculated as the difference between active-Vessel Speed Reduction (VSR) periods for blue whales during 2015 to 2017 and control period speeds for (a) pre- and (b) inactive-VSR periods. Blue corresponds to mortality that declined during VSR and red to mortality that increased during VSR (since the metric subtracts VSR from no VSR). The top color scale applies to the top row of the maps (a) and the bottom scale to the bottom row (b)

tional to the simulated change in cooperation but that the slopes of the linear fits varied across years (Figs. S2 \& S3 in the Supplement). Achieving a 1\% decline in mortality required a $3 \%$ increase in vessels comporting with a $10 \mathrm{kn}$ speed limit in 20142015 , compared to $4 \%$ required in 2016-2017. A simulated $10 \mathrm{kn}$ speed limit always resulted in a greater decline of mortality than a $12 \mathrm{kn}$ limit. The greatest predicted decrease in mortality for a $10 \mathrm{kn}$ speed limit was $25.6 \%$ (Table 7 ) while the greatest decrease in mortality for $12 \mathrm{kn}$ was $18 \%$ (Table S4 in the Supplement). Of all estimates, the highest coefficient of variation was $3.2 \%$, representing a prediction error of less than 0.01 deaths per month from the random simulation process.

Within potential SMA areas, the $10 \mathrm{kn}$ scenarios resulted in a $4 \%$ decline in mortality for each $10 \%$ increase in compliant vessels (Fig. S3). Maximum potential decreases in mortality were significantly higher than in TSS scenarios, reaching a projected $35 \%$ decline for blue whales and a 31\% decline for humpback whales (Table 8).

\section{DISCUSSION}

Decreasing ship strikes has been a challenging task around the world (Clapham et al. 1999, Laist et al. 2001, van der Hoop et al. 2013). Until recently, however, concerns over the problem were based on beached carcasses (which can, by definition, constitute only an absolute minimum estimate of shipstrike death rates) and highly uncertain stranding rate extrapolations of mortality. Modeling approaches (Rockwood et al. 2017) provided new estimates of strike mortality rates within the EEZ off California, Oregon and Washington which exceeded PBR in some cases. To enhance management and reduce the 

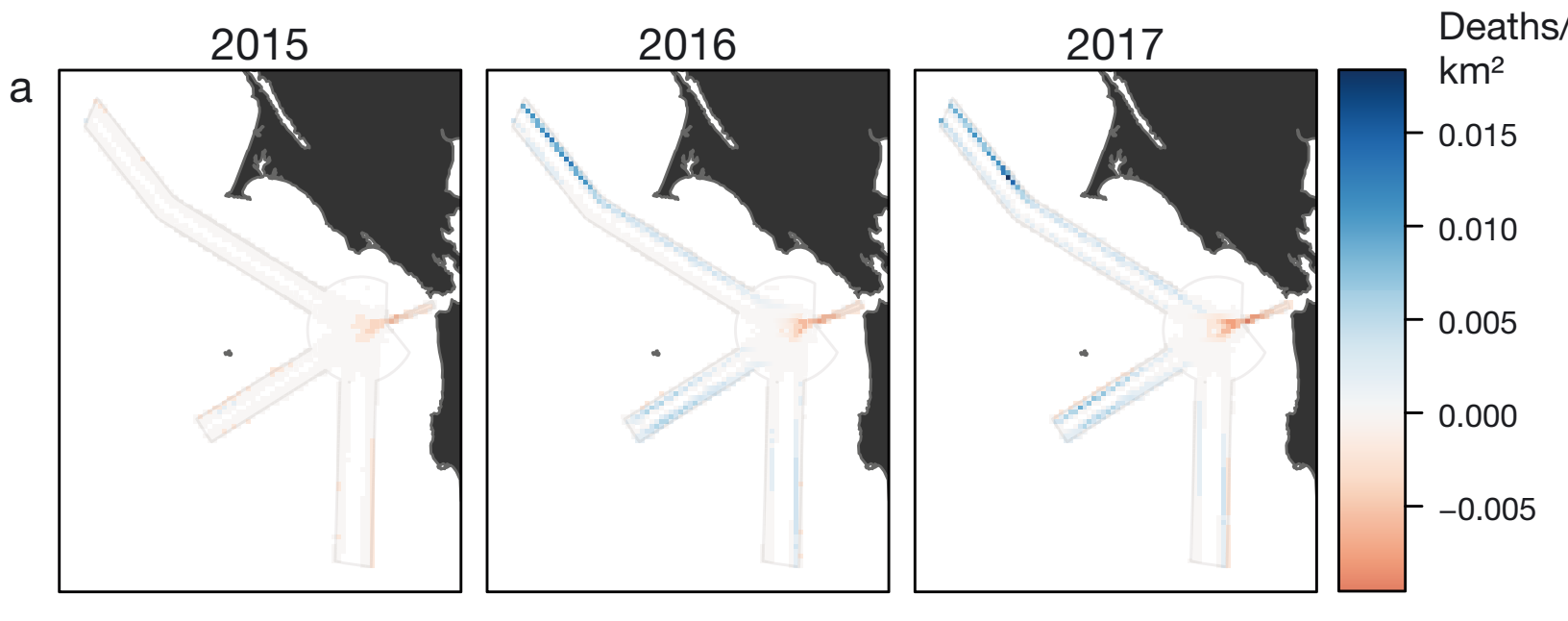

b
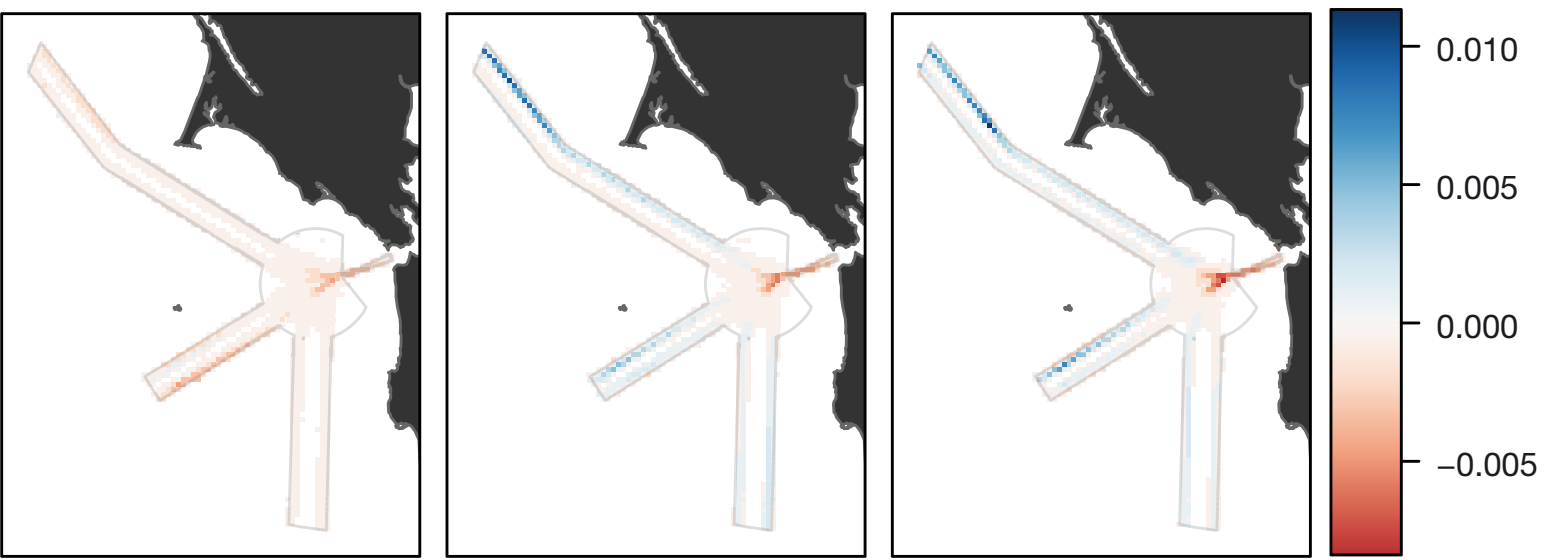

Fig. 10. Difference between mortality calculated as the difference between active-Vessel Speed Reduction (VSR) periods for humpback whales during 2015 to 2017 and control period speeds for (a) pre- and (b) inactive-VSR periods. Blue corresponds to mortality that declined during VSR and red to mortality that increased during VSR (since the metric subtracts VSR from no VSR). The top color scale applies to the top row of the maps (a) and the bottom scale to the bottom row (b)

probability of fatal ship strikes, we assessed mortality using a refined encounter model approach, finescale whale density predictions and novel simulation approaches in the San Francisco TSS and surrounding waters. The results of this work will enable improved strategies for reduction of ship strikes in this high mortality area, and our approach holds promise for application to other high risk regions and whale populations around the world at-risk from strikes.

\subsection{Overall mortality and comparison to EEZ-wide results}

Strike mortality and co-occurrence of whales and ships have been known problems in our study area for years (Dransfield et al. 2014). Our results back previous findings that the area has high strike mortality for blue and humpback whales. As compared to previous strike mortality predictions which used long-term whale density averages, this research used monthly whale density. In addition, the improved model formulation, which calculates expected encounters for each vessel transit independently, captures non-linear relationships between mortality and speed. This improvement is especially important for comparisons between time periods or simulated scenarios, as were made here.

The results of this study provide significantly higher estimates of mortality than the broad-scale assessment of Rockwood et al. (2017), especially for blue whales (Table 1). The discrepancy arises from (1) our use of individual ship tracks (instead of ship variables averaged across grid cells) and (2) high-resolution whale density models built on extensive survey coverage of the continental shelf (instead of broad surveys of the EEZ). For example, in contrast to our model (Fig. 2), the blue whale model described by Becker et al. (2016) predicts high density 40 to $60 \mathrm{~km}$ north and south of the San Francisco Bay harbor 
Table 7. Percent decrease in predicted mortality in the TSS relative to reference mortality for $10 \mathrm{kn}$ cooperation scenarios ranging from 30 to $95 \%$ target cooperation. (-) No simulation possible

\begin{tabular}{|c|c|c|c|c|c|c|c|c|}
\hline \multirow{4}{*}{$\begin{array}{l}\text { Adherence to } 10 \mathrm{kn} \text { speed (\%) } \\
\text { Reference mortality }\end{array}$} & \multicolumn{4}{|c|}{ _ Blue whale __ } & \multicolumn{4}{|c|}{-Humpback whale - } \\
\hline & 2014 & 2015 & 2016 & 2017 & 2014 & 2015 & 2016 & 2017 \\
\hline & 22.8 & 29.2 & 43.3 & 40.4 & 22.8 & 29.2 & 43.3 & 40.4 \\
\hline & 0.80 & 0.83 & 2.16 & 1.93 & 4.90 & 5.21 & 7.46 & 8.54 \\
\hline \multicolumn{9}{|c|}{ Predicted decrease in mortality (\%) (pre-VSR) } \\
\hline $30 \%$ cooperation & 3.3 & - & - & - & 3.3 & - & - & - \\
\hline $40 \%$ cooperation & 6.7 & 3.2 & - & - & 6.6 & 3.3 & - & - \\
\hline $50 \%$ cooperation & 10.4 & 6.2 & 1.3 & 2.2 & 10.4 & 6.4 & 1.5 & 2.2 \\
\hline operation & 13.8 & 9.2 & 3.6 & 4.3 & 13.7 & 9.4 & 3.9 & 4.6 \\
\hline $70 \%$ cooperation & 16.7 & 12.2 & 5.8 & 6.8 & 16.5 & 12.4 & 6.1 & 7.1 \\
\hline $80 \%$ cooperation & 20.2 & 15.4 & 8.3 & 9.0 & 20.1 & 15.6 & 8.7 & 9.3 \\
\hline $85 \%$ cooperation & 22.6 & 16.7 & 9.4 & 10.2 & 22.4 & 17.0 & 10.0 & 10.5 \\
\hline $90 \%$ cooperation & 23.7 & 18.5 & 10.5 & 11.1 & 23.6 & 18.7 & 11.0 & 11.7 \\
\hline $95 \%$ cooperation & 25.6 & 19.9 & 11.7 & 12.4 & 25.4 & 20.1 & 12.4 & 12.9 \\
\hline
\end{tabular}

Table 8. Percent decrease in predicted mortality in the predicted SMA areas relative to actual for $10 \mathrm{kn}$ cooperation scenarios ranging from 30 to $95 \%$ target cooperation

\begin{tabular}{|c|c|c|c|c|c|c|c|c|}
\hline \multirow{4}{*}{$\begin{array}{l}\text { Actual year cooperation (\%) } \\
\text { Actual mortality (active-VSR) }\end{array}$} & \multicolumn{4}{|c|}{ _ Blue whale __ } & \multicolumn{4}{|c|}{ - Humpback whale - } \\
\hline & 2014 & 2015 & 2016 & 2017 & 2014 & 2015 & 2016 & 2017 \\
\hline & 16.3 & 20.9 & 24.2 & 22.3 & 16.3 & 20.9 & 24.2 & 22.3 \\
\hline & 1.00 & 1.60 & 2.03 & 1.47 & 1.72 & 2.01 & 2.51 & 2.94 \\
\hline \multicolumn{9}{|c|}{ Predicted decrease in mortality (\%) (pre-VSR) } \\
\hline $30 \%$ cooperation & 7.3 & 3.6 & 1.3 & 3.6 & 6.2 & 3.5 & 1.7 & 3.1 \\
\hline $40 \%$ cooperation & 11.2 & 7.3 & 5.0 & 7.2 & 9.9 & 7.4 & 5.1 & 6.5 \\
\hline $50 \%$ cooperation & 16.8 & 11.9 & 8.6 & 11.4 & 14.6 & 11.4 & 8.5 & 10.4 \\
\hline $60 \%$ cooperation & 21.0 & 16.0 & 12.2 & 14.8 & 18.3 & 14.7 & 11.8 & 13.6 \\
\hline $70 \%$ cooperation & 23.3 & 20.5 & 15.9 & 19.4 & 20.8 & 18.5 & 15.2 & 17.2 \\
\hline $80 \%$ cooperation & 27.7 & 24.3 & 19.5 & 22.6 & 24.9 & 22.5 & 18.5 & 20.6 \\
\hline $85 \%$ cooperation & 29.9 & 26.6 & 21.3 & 24.5 & 26.6 & 24.4 & 20.2 & 22.5 \\
\hline $90 \%$ cooperation & 33.3 & 28.5 & 23.1 & 26.4 & 29.5 & 26.0 & 22.0 & 24.2 \\
\hline $95 \%$ cooperation & 35.1 & 30.6 & 25.4 & 28.3 & 31.2 & 27.9 & 23.9 & 26.0 \\
\hline
\end{tabular}

abundance and predicted mortality. In some years, whales concentrated strongly at the shelf break, while in others they were more diffusely distributed across the shelf (Rockwood et al. 2020), highlighting the influence of whale behavior and ecology on predicted strike mortality.

While some years (notably 2016) showed high mortality for both species, there were significant differences in the annual mortality patterns (Fig. 3), showing the complexity of managing ship strikes for multiple whale species. Stranded ship-struck blue whales were found in the region in 2016 and 2017, 2 of the years with the highest mortality predicted by our models. One humpback whale shipstruck carcass was recorded each year in 2013, 2015 and 2016. Predicted mortality was lowest for 2013, but highest in 2015 and 2016, suggesting that while the years with highest modeled mortality may be most likely to have strandings, dead whales still may reach the shore even in lower predicted mortality years. This emphasizes the stochasticity in the relationship between the actual number of shipstruck whales and the number of stranding reports. Alternate mortality indicators aside from strand-

mouth, but not overlapping the majority of the TSS. Our higher mortality estimates add evidence that ship-strike mortality likely exceeds PBR for blue whales and probably for humpback whales.

Annual variation of estimated mortality was notable (Fig. 3), and correlated strongly with whale abundances. This suggests that local changes in whale abundance can have strong effects on both inter-annual and long-term patterns of ship-strike mortality. From 2012 to 2017, the moderating effect on mortality of decreasing vessel speeds was overshadowed by growing whale abundances in the region; mortality increased through the study years, especially for humpback whales. Variation in spatial distributions of whales within the study area also influenced predicted mortality rates and accounted for break-downs in correlation between total whale ings, such as those presented here, help circumvent that stochasticity. The relationship between our predictions and numbers of recovered ship-struck whale carcasses also reinforces that strandings represent a small fraction of the mortality (Williams et al. 2011, Redfern et al. 2013, Rockwood et al. 2017).

\subsection{Implications of spatial patterns}

As expected from previous models (Dransfield et al. 2014), photo ID records (Calambokidis et al. 2015) and $15 \mathrm{yr}$ of ACCESS survey observations, the areas where TSSs intersect the shelf break were the highest mortality locations for both species (Figs. 4-7). The greater total abundance and broader distribution of humpback whales across the shelf 
and near the mouth of San Francisco Bay played a key role in elevated total mortality compared to blue whales (Fig. 2). The Bay lane and precautionary zone experience the combined traffic from all 3 approach lanes, driving high mortality predictions for humpback whales despite slower speeds in those areas.

Some risk exists in all lanes throughout the months considered, especially for humpback whales, but regions inshore of Cordell Bank and near the shelf break in the Western lanes were consistently highest (Fig. 4). In addition, the areas just beyond the ends of the Northern and Western lanes had high predicted mortality for both species, especially in June, July and September (Figs. 5 \& 6). Since 47 and $65 \%$ of blue and humpback whale mortality, respectively, is within the lanes (Table 3), understanding where the remainder of risk falls is vital for effective management. The areas outside the TSS but within the 50th percentile area (Fig. 7, Table 2) hold 48 and $33 \%$ of the mortality for blue and humpback whales, respectively. The addition of speed limit SMAs in these locations would greatly enhance the effect of the existing VSR on whale mortality.

In particular, if speed limits in the lanes had high cooperation and SMAs were established at the end of each lane (Fig. 7), 95\% or more of the mortality in the study area could be addressed for both species. Similar to the conclusions of Rockwood et al. (2017), our results suggest that the greatest reduction in the occurrence of ship strikes will require efforts both inside and outside the TSSs. We have pinpointed the areas at the seaward ends of the TSSs and defined potential SMAs (Fig. 7).

\subsection{Distribution of mortality and risk across management jurisdictions}

The Northern and Western lanes, especially in the outbound direction, were responsible for the majority of predicted mortality in the TSS (Table S1). The patterns of mortality within the different portions of the lanes illustrate the complexity and nuances of the management problem. The VSR program implemented by national marine sanctuaries includes outreach and communication with the shipping industry. Results from this analysis, such as faster speeds observed in the outbound Northern and Western lanes and increases in Bay lane speeds during active VSRs, are topics for engagement with the shipping industry to further decrease ship strike occurrence.

\subsection{Predicted changes in mortality from decreased speed and VSR cooperation}

Vessel speeds in the study area declined from 2012 to 2017, with the greatest decline from 2015-2016, during the second year of the voluntary VSR program (Fig. 8). Similarly, adherence to voluntary 10 and $12 \mathrm{kn}$ speed limits increased in 2016 and 2017 compared to the 2012-2014 pre-VSR baseline. There has been a clear long-term trend of slowing vessel speeds in our study area and elsewhere along the California coast (Moore et al. 2018). Average vessel speeds dropped from 16 to $14 \mathrm{kn}$ between 2012 and 2016 to increase fuel efficiency and decrease costs in response to emissions control regulations. Given this trend, it is not possible to attribute the speed declines that we calculated for 2012 to 2017 to the VSR. However, speeds before and after VSR implementation (initiated in 2015) were different (Fig. 8) and the sharp decline from the first to second year of the VSR (2015 to 2016) suggests VSRs played a role in these declines in average vessel speeds.

Simulated changes in mortality from speeds during the pre-VSR period to those observed in 2015-2017 were relatively small. In 2015, simulated mortality levels actually increased compared to both control estimates and for both species (Tables $5 \& 6$ ). These increases were counterintuitive to the small increases in cooperation levels observed. However, the nonlinear relationship between speed and estimated mortality levels means that both mean speed and cooperation level are imperfect predictors of change in mortality (see Fig. S4 in the Supplement). In 2015, during the VSR, vessels with high speeds contributed disproportionately to predicted mortality, and higher speeds also overlapped more with elevated whale density. Simple metrics like mean speed and cooperation are helpful to understand likely coarse-level effects of VSRs on rates of fatal strikes. However, when changes in those summary metrics are small, it is important to consider the distribution of speed values (rather than a summary metric like the mean) and where they occur in space in order to make reliable predictions of effects on mortality.

The simulated mortality decreases in 2016-2017 relative to pre-VSR are approximately equivalent to avoiding 1 blue whale ship strike every $4 \mathrm{yr}$ and 1 humpback whale death every $1.4 \mathrm{yr}$ within the TSS. This relatively small decrease comes in part because vessel speeds had already declined to an average of $12.28 \mathrm{kn}$ in 2012-2014. The greatest reductions in mortality occur when there are large differences between unregulated and compliant speeds (especially for initial speeds up to approximately $20 \mathrm{kn}$ ). There- 
fore, the lower starting speeds in our study area preclude greater declines in mortality risk without high cooperation levels.

The changes in ship speeds and thus expected mortality rates were not uniform across space. We found that declines in mortality during the VSR occurred in the offshore ends of the lanes but increases occurred in the shoreward portion of the precautionary zone and the Bay lane. Vessel travel after the pilot is brought on board (in the precautionary zone) is faster during the VSR compared to control periods. Since the precautionary zone and the Bay lane have not been part of the VSR to date, this pattern offers an opportunity for decision makers to work with pilots and shipping companies to counteract this trend.

Neither the pre- nor inactive-VSR simulations can entirely control for all non-VSR driven patterns in speed. The inactive-VSR simulations control for the long-term decline in vessel speeds by using a control period within the same year but not for seasonal patterns. The difference in mean speeds between seasons was $0.09 \mathrm{kn}$ (inactive > active-VSR season) while the difference between pre-VSR and activeVSR years was $0.27 \mathrm{kn}$. Thus, the pre-VSR simulation was a slight overestimate of the effect of the VSR on whale strike mortality while the inactive-VSR simulation was an even smaller underestimate. The difference between the pre-VSR and inactive-VSR mortality changes can then be taken as a slight overestimate of the effect of the long-term decline in speeds. Through this partitioning, we estimated that approximately $5.8 \%$ of blue and $5.4 \%$ of humpback whale mortality decreases were a result of the longterm speed decline. Thus, the long-term decline in speeds has helped decrease ship-strike mortality in our study area, but only slightly. However, long-term speed decreases occurred over a much broader area (Moore et al. 2018), and so may have resulted in nontrivial decreases in ship strikes EEZ-wide. The magnitude of those decreases remains unknown.

\subsection{Management scenarios and the future of whale-strike mitigation}

Simulation of ship operators' adherence to prescribed speeds and speed limit scenarios confirmed the need for high mariner cooperation to achieve significant declines in mortality rates (Tables 5, 6, S4 \& S5, Figs. S2 \& S3). With target cooperation of $95 \%$ and a $10 \mathrm{kn}$ speed limit, predicted mortality would be $26 \%$ lower compared to the 2012-2014 pre-VSR baseline. Thus, when whale densities and vessel characteristics are similar to 2014, a $10 \mathrm{kn}$ limit in the lanes alone and $95 \%$ cooperation would equate to potentially reducing the number of humpback whale deaths by 1.1 in the 4 month period.

When comparing simulation results, it is clear that a $10 \mathrm{kn}$ speed limit will have a much greater effect on fatal strike rates than a $12 \mathrm{kn}$ limit (Figs. S2-S4). Decreases in mortality compared to pre-VSR for a $12 \mathrm{kn}$ limit exhibited a maximum decline of $20 \%$ (Fig. S2C,D), whereas decreases for the $10 \mathrm{kn}$ scenarios reached $28 \%$ (Fig. S2A,B). Decision makers will need to weigh the additional declines in predicted strike mortality achieved with $10 \mathrm{kn}$ speeds (versus $12 \mathrm{kn}$ ) against the economic and safety concerns of shipping operators.

The $10 \mathrm{kn}$ vessel speed restrictions established in certain areas to reduce strike occurrence of North Atlantic right whales have resulted in reduced vessel-strike mortality rates in the range of 56 to $90 \%$ (Wiley et al. 2011, Conn \& Silber 2013). These decreases were well above the maximum $26 \%$ reduction we found in our TSS scenario simulations or the $35 \%$ reduction in the SMA scenarios. A major factor contributing to this is the difference in vessel speed distributions prior to implementation of eastern seaboard SMAs as compared to the initial speed conditions currently in our study area. Whereas our initial (reference) mean vessel speeds ranged from 12.1 to $11.6 \mathrm{kn}$ in 2014 to 2017, vessel speeds in eastern seaboard SMAs averaged around $15 \mathrm{kn}$ in 2006, prior to implementation of the regulation (Lagueux et al. 2011, Laist et al. 2014). Therefore, as a result of various factors, including air pollution regulations, our risk reduction projections were less than those where right whale SMAs were established; the difference between pre- and post-implementation of ship-strike reduction measures was less pronounced.

We found that speed limits in hypothetical SMAs exhibited greater strike risk reduction (up to $35 \%$ for blue whales and $24 \%$ for humpback whales) than speed reduction scenarios in the TSSs. This finding both highlights successes to date in the TSS (which have already secured some of the possible reduction in mortality) and the need for (1) greater cooperation by vessel operators and (2) additional areas with limited speed if further decreases in ship-strike mortality are desired.

\subsection{Conclusions}

Vessel-strike mortality is an established mortality source for large whale populations around the world (Berman-Kowalewski et al. 2010, David et al. 2011, 
Redfern et al. 2013, McKenna et al. 2015, Priyadarshana et al. 2016, Nichol et al. 2017, Rockwood et al. 2017). Researchers continue to explore new technologies such as acoustic and infrared detection and real-time reporting (Couvat \& Gambaiani 2013, Horton et al. 2017, Baumgartner et al. 2019), regulatory approaches (Silber et al. 2012b, Sèbe et al. 2019), best navigational practices (Williams et al. 2016, Gende et al. 2019) and new conceptual frameworks (Pirotta et al. 2019) to decrease ship strikes. Nonetheless, speed restrictions remain one of the most studied and proven methods to avoid strike deaths (Leaper 2019, Schoeman et al. 2020). This work uses the fine-scale patterns of modeled mortality in vessel approaches to the San Francisco Bay port complexes, one of the highest risk regions along the entire coast (Rockwood et al. 2017), as a study system to apply new ways to predict and evaluate ship-strike management decisions. Our approach provides broadly applicable tools that can help reduce the occurrence of strikes and estimate strike mortality to help decision makers choose what actions, if any, are needed to ensure healthy whale populations.

Most notably, our research identifies regions beyond the terminus of the TSS that could significantly decrease strike mortality if SMAs with established speed limits were introduced. In addition, our simulations suggest that the small decreases in average vessel speeds and increases in VSR cooperation over the last 3 years may have resulted in minor decreases in the number of strikes. Model scenarios show that mariner adherence to recommended speed limits would need to expand to levels above $80 \%$ and continued use of a $10 \mathrm{kn}$ speed limit would be necessary to maximize potential strike mitigation. The maximum reduction in mortality predicted for 2014-2017 with a $10 \mathrm{kn}$ speed limit and $95 \%$ cooperation in the TSS was 1.1 humpback whales and 0.2 blue whales in a 4 month period. Our projections suggest that if 3 SMAs accompanied by $10 \mathrm{kn}$ speed restrictions were established adjacent to the ends of the existing TSSs, an additional average of 0.77 humpback whale and 0.52 blue whale deaths per 4 month period might be averted. On the eastern seaboard and in southern California, high levels of cooperation have only been achieved with port incentive programs (Freedman et al. 2017) or mandatory regulations and enforcement (Silber et al. 2014, Redfern et al. 2019). Therefore, alternatives to the existing voluntary VSR measures may be necessary to achieve significant reductions in the number of ship-strike deaths. Our modeling effort suggests that for ship-strike mortality of blue and humpback whales to be below the current PBR levels, additional ship traffic management will be necessary in our study area and elsewhere in California waters.

As the impacts of ship strikes on marine animals around the world are evaluated further, it is important to understand how best to address the problem. When possible, using multiple approaches is likely to achieve the greatest reduction in deaths (Silber et al. 2012b, Couvat \& Gambaiani 2013). In addition, there are increasing calls to move toward a more holistic and geographically extensive approach to ship strikes (Rockwood et al. 2017, Pirotta et al. 2019, Sèbe et al. 2019) and inclusion of economic tradeoffs and consequences of whale strikes and their management (Freedman et al. 2017, Gonyo et al. 2019, Sèbe et al. 2019). The approach developed here can help evaluate speed restrictions and their enforcement both before and after implementation and has the potential to incorporate economic considerations and be applied across a range of spatial scales. Such assessments will play an important role in developing and implementing an effective holistic approach to decreasing ship-strike impacts to marine wildlife.

Acknowledgements. We thank Julie Howar for providing GIS data. We also thank John Calambokidis and Angela Szesciorka for compiling and analyzing tag data for time at depth calculations. John Calambokidis, Angela Szesciorka, James Fahlbusch and Nathan Harrison developed and deployed whale tags. Earlier versions of this manuscript were greatly improved by comments from John Calambokidis, Dan Howard, Dani Lipski, Michael Carver, Jan Roletto, Shannon Bettridge, Eric Patterson and Caroline Good. Whale data was collected by the Applied California Current Ecosystem Studies (ACCESS, www.accessoceans.org), a partnership between Point Blue Conservation Science, Cordell Bank National Marine Sanctuary and Greater Farallones National Marine Sanctuary. This analysis was funded by NOAA Cordell Bank National Marine Sanctuary Contract RA133C17SE1024, with additional funding from Battery Powered and the Gordon and Betty Moore Foundation. Funding for ACCESS and whale spatial modeling was provided in part by the Angell Family Foundation, Bently Foundation, Bonnell Cove Foundation, Boring Family Foundation, California Sea Grant, Elinor Patterson Baker Trust, Faucett Catalyst Fund, Firedoll Foundation, Hellman Family Foundation, Moore Family Foundation, National Fish and Wildlife Foundation, Office of National Marine Sanctuaries, Pacific Life Foundation, Resources Legacy Fund, Thelma Doelger Trust for Animals and Point Blue donors.

\section{LITERATURE CITED}

Abramson L, Polefka S, Hastings S, Bor K (2010) Reducing the threat of ship strikes on large cetaceans in the Santa Barbara Channel Region and Channel Islands National Marine Sanctuary: recommendations and case studies. Marine Sanctuaries Conservation Series ONMS-11-01. US Department of Commerce, NOAA, Office of National Marine Sanctuaries, Silver Spring, MD 
Baumgartner MF, Bonnell J, Van Parijs SM, Corkeron PJ and others (2019) Persistent near real-time passive acoustic monitoring for baleen whales from a moored buoy: system description and evaluation. Methods Ecol Evol 10:1476-1489

Becker EA, Forney KA, Fiedler PC, Barlow J and others (2016) Moving towards dynamic ocean management: how well do modeled ocean products predict species distributions? Remote Sens 8:149

Berman-Kowalewski M, Gulland FMD, Wilkin S, Calambokidis $\mathrm{J}$ and others (2010) Association between blue whale (Balaenoptera musculus) mortality and ship strikes along the California coast. Aquat Mamm 36: 59-66

Bettridge S, Baker CS, Barlow J, Clapham PJ and others (2015) Status review of the humpback whale (Megaptera novaeangliae) under the Endangered Species Act. NOAA Tech Memo NMFS-SWFSC-540

Bezamat C, Wedekin LL, Simões-Lopes PC (2015) Potential ship strikes and density of humpback whales in the Abrolhos Bank breeding ground, Brazil. Aquat Conserv 25:712-725

Calambokidis J, Barlow J (2013) Updated abundance estimates of blue and humpback whales off the US west coast incorporating photo-identifications from 2010 and 2011. Final Report for contract AB-133F-10-RP-0106. PSRG-2013-13R. Cascadia Research, Olympia, WA

Calambokidis J, Steiger GH, Curtice C, Harrison J and others (2015) Biologically important areas for selected cetaceans within U.S. waters - west coast region. Aquat Mamm 41:39-53

Carretta JV, Muto MM, Wilkin S, Greenman J and others (2016a) Sources of human-related injury and mortality for U.S. Pacific west coast marine mammal stock assessments, 2010-2014. NOAA Tech Memo NMFS-SWFSC601

Carretta JV, Oleson EM, Baker J, Weller DW and others (2016b) U.S. Pacific marine mammal stock assessments: 2015. NOAA Tech Memo NMFS-SWFSC-561

Carretta JV, Forney KA, Oleson EM, Weller DW and others (2018) U.S. Pacific marine mammal stock assessments: 2017. NOAA Tech Memo NMFS-SWFSC-602

Clapham PJ, Young SB, Brownell RL Jr (1999) Baleen whales: conservation issues and the status of the most endangered populations. Mammal Rev 29:37-60

Conn PB, Silber GK (2013) Vessel speed restrictions reduce risk of collision-related mortality for North Atlantic right whales. Ecosphere 4:43

Couvat J, Gambaiani D (2013) Evaluation of the technical solutions and management measures implemented at the international level to reduce the risks of collisions between ships and large cetaceans. Souffleurs d'Ecume, Brignoles

Crum N, Gowan T, Krzystan A, Martin J (2019) Quantifying risk of whale-vessel collisions across space, time, and management policies. Ecosphere 10:e02713

David L, Alleaume S, Guinet C (2011) Evaluation of the potential of collision between fin whales and maritime traffic in the north-western Mediterranean Sea in summer, and mitigation solutions. J Mar Anim Ecol 4:17-28

Dransfield A, Hines E, McGowan J, Holzman B and others (2014) Where the whales are: using habitat modeling to support changes in shipping regulations within National Marine Sanctuaries in Central California. Endang Species Res 26:39-57
Fossette S, Abrahms B, Hazen EL, Bograd SJ and others (2017) Resource partitioning facilitates coexistence in sympatric cetaceans in the California Current. Ecol Evol 7:9085-9097

Freedman R, Herron S, Byrd M, Birney K and others (2017) The effectiveness of incentivized and non-incentivized vessel speed reduction programs: case study in the Santa Barbara channel. Ocean Coast Manage 148:31-39

* Gende SM, Hendrix AN, Harris KR, Eichenlaub B, Nielsen J, Pyare S (2011) A Bayesian approach for understanding the role of ship speed in whale-ship encounters. Ecol Appl 21:2232-2240

Gende SM, Vose L, Baken J, Gabriele CM, Preston R, Hendrix AN (2019) Active whale avoidance by large ships: components and constraints of a complementary approach to reducing ship strike risk. Front Mar Sci 6:1-19

* Gonyo SB, Goedeke TL, Wolfe KE, Jeffrey CFG, Gorstein M, Poti M, Dorfman DS (2019) An economic analysis of shipping costs related to potential changes in vessel operating procedures to manage the co-occurrence of maritime vessel traffic and whales in the Channel Islands region. Ocean Coast Manage 177:179-187

* Gurarie E, Ovaskainen O (2013) Towards a general formalization of encounter rates in ecology. Theor Ecol 6: 189-202

Guzman HM, Gomez CG, Guevara CA, Kleivane L (2013) Potential vessel collisions with Southern Hemisphere humpback whales wintering off Pacific Panama. Mar Mamm Sci 29:629-642

Horton TW, Oline A, Hauser N, Khan TM and others (2017) Thermal imaging and biometrical thermography of humpback whales. Front Mar Sci 4:1-11

* Irvine LM, Mate BR, Winsor MH, Palacios DM, Bograd SJ, Costa DP, Bailey H (2014) Spatial and temporal occurrence of blue whales off the U.S. west coast, with implications for management. PLOS ONE 9:e102959

Jensen AS, Silber GK (2004) Large whale ship strike database. NOAA Tech Memo NMFS-OPR-25

* Jensen CM, Hines E, Holzman BA, Moore TJ, Jahncke J, Redfern JV (2015) Spatial and temporal variability in shipping traffic off San Francisco, California. Coast Manage 43:575-588

Lagueux KM, Zani MA, Knowlton AR, Kraus SD (2011) Response by vessel operators to protection measures for right whales Eubalaena glacialis in the southeast US calving ground. Endang Species Res 14:69-77

* Laist DW, Knowlton AR, Mead JG, Collet AS, Podesta M (2001) Collisions between ships and whales. Mar Mamm Sci 17:35-75

Laist DW, Knowlton AR, Pendleton D (2014) Effectiveness of mandatory vessel speed limits for protecting North Atlantic right whales. Endang Species Res 23:133-147

* Leaper R (2019) The role of slower vessel speeds in reducing greenhouse gas emissions, underwater noise and collision risk to whales. Front Mar Sci 6:1-8

Martin J, Sabatier Q, Gowan TA, Giraud C, Gurarie E and others (2016) A quantitative framework for investigating risk of deadly collisions between marine wildlife and boats. Methods Ecol Evol 7:42-50

*McKenna MF, Katz SL, Condit C, Walbridge S (2012) Response of commercial ships to a voluntary speed reduction measure: are voluntary strategies adequate for mitigating ship-strike risk? Coast Manage 40:634-650

McKenna MF, Calambokidis J, Oleson EM, Laist DW, Goldbogen JA (2015) Simultaneous tracking of blue whales 
and large ships demonstrates limited behavioral responses for avoiding collision. Endang Species Res 27: 219-232

Moore TJ, Redfern JV, Carver M, Hastings S, Adams JD, Silber GK (2018) Exploring ship traffic variability off California. Ocean Coast Manage 163:515-527

Nichol LM, Wright BM, O'Hara P, Ford JKB (2017) Risk of lethal vessel strikes to humpback and fin whales off the west coast of Vancouver Island, Canada. Endang Species Res 32:373-390

Peel D, Smith JN, Childerhouse S (2018) Vessel strike of whales in Australia: the challenges of analysis of historical incident data. Front Mar Sci 5:69

* Peltier H, Beaufils A, Cesarini C, Dabin W and others (2019) Monitoring of marine mammal strandings along French coasts reveals the importance of ship strikes on large cetaceans: a challenge for the European Marine Strategy Framework Directive. Front Mar Sci 6:486

Pirotta V, Grech A, Jonsen ID, Laurance WF, Harcourt RG (2019) Consequences of global shipping traffic for marine giants. Front Ecol Environ 17:39-47

Priyadarshana T, Randage SM, Alling A, Calderan S, Gordon J, Leaper R, Porter L (2016) Distribution patterns of blue whale (Balaenoptera musculus) and shipping off southern Sri Lanka. Reg Stud Mar Sci 3:181-188

R Core Team (2019) R: a language and environment for statistical computing. R Foundation for Statistical Computing, Vienna. www.r-project.org

Redfern JV, McKenna MF, Moore TJ, Calambokidis J and others (2013) Assessing the risk of ships striking large whales in marine spatial planning. Conserv Biol 27: 292-302

Redfern JV, Moore TJ, Becker EA, Calambokidis J and others (2019) Evaluating stakeholder-derived strategies to reduce the risk of ships striking whales. Divers Distrib 25:1575-1585

Robards MD, Silber GK, Adams JD, Arroyo J, Lorenzini D, Schwehr K, Amos J (2016) Conservation science and policy applications of the marine vessel Automatic Identification System (AIS) — a review. Bull Mar Sci 92:75-103

Rockwood RC, Calambokidis J, Jahncke J (2017) High mortality of blue, humpback and fin whales from modeling of vessel collisions on the U.S. West Coast suggests population impacts and insufficient protection. PLOS ONE 12: e0183052

Rockwood RC, Elliott ML, Saenz B, Nur N, Jahncke J (2020) Modeling predator and prey hotspots: management implications of baleen whale co-occurrence with krill in Central California. PLOS ONE 15:e0235603

* Schoeman RP, Patterson-Abrolat C, Plön S (2020) A global review of vessel collisions with marine animals. Front Mar Sci 7:1-25

Sèbe M, Kontovas CA, Pendleton L (2019) A decisionmaking framework to reduce the risk of collisions between ships and whales. Mar Policy 109:103697

Silber GK, Slutsky J, Bettridge S (2010) Hydrodynamics of a ship/whale collision. J Exp Mar Biol Ecol 391:10-19

Silber GK, Adams JD, Bettridge S (2012a) Vessel operator response to a voluntary measure for reducing collisions with whales. Endang Species Res 17:245-254

Silber GK, Vanderlaan ASM, Tejedor Arceredillo A, Johnson $L$ and others $(2012 b)$ The role of the International

Editorial responsibility: Robert Harcourt,

Sydney, New South Wales, Australia
Maritime Organization in reducing vessel threat to whales: process, options, action and effectiveness. Mar Policy 36:1221-1233

Silber GK, Adams JD, Fonnesbeck CJ (2014) Compliance with vessel speed restrictions to protect North Atlantic right whales. PeerJ 2:e399

* Silber GK, Adams JD, Asaro MJ, Cole TVN, Moore KS, WardGeiger LI, Zoodsma BJ (2015) The right whale mandatory ship reporting system: a retrospective. PeerJ 3:e866

Silber GK, Lettrich MD, Thomas PO, Baker JD and others (2017) Projecting marine mammal distribution in a changing climate. Front Mar Sci 4:413

S Smith JN, Kelly N, Childerhouse S, Redfern JV, Moore TJ, Peel D (2020) Quantifying ship strike risk to breeding whales in a multiple-use marine park: the Great Barrier Reef. Front Mar Sci 7:67

* Taylor BL, Martinez M, Gerrodette T, Barlow J, Hrovat YN (2007) Lessons from monitoring trends in abundance of marine mammals. Mar Mamm Sci 23:157-175

*Tournadre J (2014) Anthropogenic pressure on the open ocean: the growth of ship traffic revealed by altimeter data analysis. Geophys Res Lett 41:7924-7932

* van der Hoop JM, Vanderlaan ASM, Taggart CT (2012) Absolute probability estimates of lethal vessel-strikes to North Atlantic right whales in Roseway Basin, Scotian Shelf. Ecol Appl 22:2021-2033

* van der Hoop JM, Moore MJ, Barco SG, Cole TVN and others (2013) Assessment of management to mitigate anthropogenic effects on large whales. Conserv Biol 27: 121-133

*van der Hoop JM, Vanderlaan ASM, Cole TVN, Henry AG and others (2015) Vessel strikes to large whales before and after the 2008 Ship Strike Rule. Conserv Lett 8:24-32

Vanderlaan ASM, Taggart CT (2009) Efficacy of a voluntary area to be avoided to reduce risk of lethal vessel strikes to endangered whales. Conserv Biol 23:1467-1474

Wade PR (1998) Calculating limits to the allowable humancaused mortality of cetaceans and pinnipeds. Mar Mamm Sci 14:1-37

Wade PR, Quinn TJ II, Barlow J, Baker CS and others (2016) Estimates of abundance and migratory destination for North Pacific humpback whales in both summer feeding areas and winter mating and calving areas. Paper SC/ 66b/IA/21 submitted to the Scientific Committee of the International Whaling Commission

Wiley DN, Moller JC, Pace RM, Carlson C (2008) Effectiveness of voluntary conservation agreements: case study of endangered whales and commercial whale watching. Conserv Biol 22:450-457

*Wiley DN, Thompson M, Pace RM, Levenson J (2011) Modeling speed restrictions to mitigate lethal collisions between ships and whales in the Stellwagen Bank National Marine Sanctuary, USA. Biol Conserv 144: 2377-2381

*Williams R, Gero S, Bejder L, Calambokidis J and others (2011) Underestimating the damage: interpreting cetacean carcass recoveries in the context of the Deepwater Horizon/BP incident. Conserv Lett 4:228-233

Williams SH, Gende SM, Lukacs PM, Webb K (2016) Factors affecting whale detection from large ships in Alaska with implications for whale avoidance. Endang Species Res 30:209-223

Submitted: November 30, 2019; Accepted: July 6, 2020 Proofs received from author(s): September 17, 2020 